\title{
Invited review: Plant polyphenols and rumen microbiota responsible for fatty acid biohydrogenation, fiber digestion, and methane emission: Experimental evidence and methodological approaches
}

\author{
V. Vasta, ${ }^{1}$ M. Daghio, ${ }^{2}$ A. Cappucci, ${ }^{3}$ A. Buccioni, ${ }^{2}$ A. Serra, ${ }^{3}$ C. Viti, ${ }^{2}$ and M. Mele ${ }^{3,4 *}$ \\ ${ }^{1}$ Food Scientist, viale delle Alpi 40, 90144, Palermo, Italy \\ 2Dipartimento di Scienze delle Produzioni Agro-Alimentari e dell'Ambiente, University of Florence, Piazzale delle Cascine 18, 50144 Firenze, Italy \\ ${ }^{3}$ Dipartimento di Scienze Agrarie, Alimentari e Agro-ambientali, University of Pisa, Via del Borghetto 80, 56124 Pisa, Italy \\ ${ }^{4}$ Centro di Ricerche Agro-ambientali “E. Avanzi," University of Pisa, Via Vecchia di Masrina, 6, 56100 Pisa, Italy
}

\section{ABSTRACT}

The interest of the scientific community in the effects of plant polyphenols on animal nutrition is increasing. These compounds, in fact, are ubiquitous in the plant kingdom, especially in some spontaneous plants exploited as feeding resources alternative to cultivated crops and in several agro-industry by-products. Polyphenols interact with rumen microbiota, affecting carbohydrate fermentation, protein degradation, and lipid metabolism. Some of these aspects have been largely reviewed, especially for tannins; however, less information is available about the direct effect of polyphenols on the composition of rumen microbiota. In the present paper, we review the most recent literature about the effect of plant polyphenols on rumen microbiota responsible for unsaturated fatty acid biohydrogenation, fiber digestion, and methane production, taking into consideration the advances in microbiota analysis achieved in the last $10 \mathrm{yr}$. Key aspects, such as sample collection, sample storage, DNA extraction, and the main phylogenetic markers used in the reconstruction of microbial community structure, are examined. Furthermore, a summary of the new high-throughput methods based on next generation sequencing is reviewed. Several effects can be associated with dietary polyphenols. Polyphenols are able to depress or modulate the biohydrogenation of unsaturated fatty acids by a perturbation of ruminal microbiota composition. In particular, condensed tannins have an inhibitory effect on biohydrogenation, whereas hydrolyzable tannins seem to have a modulatory effect on biohydrogenation. With regard to fiber digestion, data from literature are quite consistent about a general depressive effect

Received April 27, 2018.

Accepted January 13, 2019.

*Corresponding author: marcello.mele@unipi.it of polyphenols on gram-positive fibrolytic bacteria and ciliate protozoa, resulting in a reduction of volatile fatty acid production (mostly acetate molar production). Methane production is also usually reduced when tannins are included in the diet of ruminants, probably as a consequence of the inhibition of fiber digestion. However, some evidence suggests that hydrolyzable tannins may reduce methane emission by directly interacting with rumen microbiota without affecting fiber digestion.

Key words: rumen microorganism, tannin, plant secondary compound, volatile fatty acid

\section{INTRODUCTION}

In the last decades animal nutritionists have increasingly focused on the physiology of the rumen and of its microorganisms as the digestion and the following utilization of feed is highly affected by ruminal fermentation. It is widely accepted that feed utilization in the rumen is dependent on the whole consortium of ruminal microorganisms rather than on the action of specific groups or strains of microorganisms. In this perspective, some authors have referred to the ruminant-microbiome association as the ruminant superorganism (Morgavi et al., 2013), evidencing the reciprocal influence between an animal's physiological condition and its microbial ecosystem. It has been demonstrated that rumen microbiome is affected by inter-individual variability (Jami and Mizrahi, 2012), by animal age and physiological state such as lactation (Jami et al., 2013; Dieho et al., 2017), and by animal diet (Belanche et al., 2012; Ellison et al., 2017). Henderson et al. (2015) observed that, regardless of the geographical distribution and animal genetics, dietary factors have a dominating effect on rumen microbial consortium composition. Several studies reported that shifts in ruminal microorganism composition and abundance are induced not only by the type of feed (i.e., grain-rich diet vs. 
fresh-forage-based diets; Fernando et al., 2010; Grilli et al., 2016) but also by dietary plant secondary compounds (PSC) such as phenolic compounds, saponins, and essential oils present in feed either naturally or supplemented (Vasta and Luciano, 2011).

The interest of the scientific community in the effects of PSC on animal nutrition is greatly increasing. These compounds, in fact, are ubiquitous in the plant kingdom, especially in some spontaneous plants exploited as feeding resources alternative to cultivated crops and in several agro-industry by-products (i.e., olive pomace, grape marc, citrus pulp). The use of local feed resources such as spontaneous plants, by-products, and food waste is considered a feasible strategy to reduce water and land consumed at a global level (Makkar and Ankers, 2014; Flachowsky et al., 2017).

Among PSC, different kinds of polyphenols (PP) are present, ranging from simple phenolic molecules to highly polymerized compounds (Bravo, 1998). Polyphenols have been shown to modulate ruminal metabolism (Makkar, 2003), growth performance, health status (Silanikove et al., 2001), and product quality (Vasta and Luciano, 2011). All these effects seem to be due to a remarkable influence of PP upon ruminal microbial environment. So far, many hypotheses have been proposed about the possible mechanisms of interaction between PP, ruminal microorganisms, and ruminal metabolites. Many studies focused, both in vitro and in vivo, on the effects of PP on individual cultivable ruminal bacterial strains, and their enzymatic pool and metabolites (Jones et al., 1994; Vasta et al., 2009a), with a reductionist approach. Recent advances in molecular analytical techniques have allowed a more holistic approach to rumen studies, giving a new insight onto the effects of PP on ruminal microbiome, as defined by Lederberg and McCray (2001): the microbial community and its genome in a specific habitat.

The aim of the present review is to outline the effects of dietary PP on ruminal microbiota composition and the implications on fatty acid biohydrogenation (BH), fiber digestion, and methane production.

\section{RUMEN MICROBIOTA ANALYSIS}

Studies on ruminal environment were initiated during the 1950s when the microbiology on rumen fermentative systems was established (Hungate, 1966). Bacteria (domain Bacteria), methanogens (domain Archaea), protozoa (domain Eukarya), and anaerobic fungi (domain Eukarya) are the key microorganisms in rumen ecosystems. They live in a relationship that leads to the utilization of ingested OM, comprising plant structural carbohydrates (lignin, cellulose, hemicelluloses, and pectins).
Early studies on ruminal microbial community focused mostly on the isolation of specific cultivable microorganisms and on the characterization of their fermentative activity (Dehority, 1966). Caldwell and Bryant (1966) were able to assess quantitative and qualitative differences in dominant bacterial groups present in the rumen content of animals fed corn-urea, corn-soybean, or alfalfa hay and grain and identified the following bacteria: Butyrivibrio sp., Succinivibrio sp., Selenomonas sp., Lachnospira sp., Succinomonas sp., Bacteroides ruminicola, Bacteroides succinogenes, Bacteroides amylophilus, Eubacterium ruminantium, Peptostreptococcus elsdenii, Ruminococcus sp., plus unidentified nonmotile rods and cocci. Further advances have shown that within the rumen there is a diversity in microbial composition depending on the physical substrate on which the microorganisms proliferate. Free-floating bacteria present in the liquid phase (liquid-associated bacteria; LAB), solid-phase adherent bacteria (solid-associated bacteria; SAB), and bacteria loosely adherent to the solid phase that can be detached by washing were identified by Czerkawski (1986). These groups also lead to different biochemical pathways (Bauchart et al., 1990).

Classical cultivation methods have been used extensively to study the rumen microbiota and have been fundamental to build our current knowledge (Deng et al., 2008). However, it is now ascertained that the cultivable species isolated by traditional microbiological techniques account only for 10 to $20 \%$ of total ruminal microbial community, although about 200 bacterial species and at least 100 species of protozoa and fungi were identified (McSweeney et al., 2007).

\section{Molecular Tools for the Characterization of Microbial Communities}

Because only a minor fraction of microorganisms is cultivable, molecular methods have been exploited to improve the understanding of the microbial ecosystem. Cultivation-independent methods have become popular tools for the characterization of microbial communities from a wide range of environments including the rumen (Kim et al., 2017). These strategies overcome the limitations of the traditional cultivation methods exploiting phylogenetic markers for the detection and quantification of microorganisms and offer the opportunity for significant scientific progress.

Fingerprinting techniques targeting phylogenetic markers have been largely used for the characterization of the microbial communities in rumen. Terminal RFLP (T-RFLP; Liu et al., 1997), automated ribosomal intergenic spacer analysis (Fisher and Triplett, 1999), and denaturing gradient gel electrophoresis (DGGE; Muyzer et al., 1993) have been used to compare the 
structure of microbial communities and to assess the diversity between samples (Buccioni et al., 2017; Vargas et al., 2017). Fingerprinting techniques give the possibility of describing the dynamics of microbial populations (i.e., by comparing profiles of samples collected in different conditions or at different sampling points), and even obtaining taxonomic information on the members of a certain community (e.g., by cutting and sequencing DGGE bands, or identifying characteristic restriction fragments in T-RFLP profiles). However, a detailed quantification of the populations is not possible using these approaches. For instance, by DGGE it is possible to assign quantitative information to specific taxonomic groups by exploiting the band intensity (the higher the intensity of the band, the more abundant the group), but assigning a precise relative abundance is not feasible. Furthermore, if T-RFLP is used to obtain taxonomic information, it is important to consider the sensitivity because different microorganisms can have similar restriction fragments, thus requiring the use of multiple restriction enzymes. For instance, Vargas et al. (2017) investigated the effect of different lipid supplements on the composition of microbial communities by using the T-RFLP technique and adopting HhaI, HaeIII, and $M s p \mathrm{I}$ as restriction enzymes.

Quantitative PCR (qPCR) is a method widely applied for the quantification of specific genes, or microbial groups, in several environments, including the rumen (Tajima et al., 2001; Belanche et al., 2012; Buccioni et al., 2015a). This approach is sensitive and rapid; furthermore, domain-specific, phylum-specific, and genus-specific primer pairs have been developed to characterize the rumen microbiota (Kim et al., 2017). When small subunit rRNA genes are used for the quantification, it is important to consider that multiple copies are present in the genome; therefore, the gene copy number is not directly linked to the number of cells in the sample. However, because the bias is likely constant between samples, qPCR can be used to quantify relative shifts of the targeted populations, even when domainspecific primer sets are used (Bertolini et al., 2013; Daghio et al., 2015). The above-mentioned cultivation independent tools offered powerful opportunities for the characterization of the diversity and the function of rumen microorganisms. The possibility to perform a detailed characterization of the microbial communities has been further expanded by the development of nextgeneration sequencing (NGS). The key steps to use an NGS approach for the characterization of microbial communities are described in the following sections.

Sample Collection, Conservation, and Nucleic Acid Extraction. A critical aspect for the characterization of the rumen microbial communities is linked to the sampling procedure that should allow the collection of a representative sample (Kim et al., 2017). Rumen cannula and esophageal probe are 2 common methods adopted to sample the rumen content. The former method allows the collection of representative and repeated sample of rumen content, even if it is more expensive and invasive (the rumen cannula is implanted by surgery) compared with the esophageal probe. By contrast, samples of rumen content by esophageal probe could be subjected to saliva contamination, and it is not easy to obtain rumen samples from the same layer of the rumen when samplings are repeated several times (Terré et al., 2013; Paz et al., 2016). In literature, the effect of the sampling method on the bacterial community composition in cows, sheep, and goats has been assessed (Ramos-Morales et al., 2014; Paz et al., 2016). Overall, the esophageal probe allowed obtaining representative samples comparable to those collected by the rumen cannula. Moreover, the esophageal probe is also considered a feasible way to increase the number of animals in each experiment, enforcing the statistical power, or when the experimental design does not allow the application of invasive techniques (Ramos-Morales et al., 2014; Paz et al., 2016).

After collection, rumen samples must be properly stored to allow a correct characterization of the microbial communities. In fact, it was demonstrated that the storage method and the storage time can significantly affect the efficiency of nucleic acid extraction and the abundance of specific taxonomic groups in the sample. Granja-Salcedo et al. (2017) recommended the storage of samples of rumen content at $-80^{\circ} \mathrm{C}$, avoiding the storage at $-20^{\circ} \mathrm{C}$. When RNA must be extracted, the use of stabilizing agents (e.g., RNAlater) is a further critical aspect, with bacterial mRNA being rapidly degraded (Simister et al., 2011; Reck et al., 2015).

To use molecular tools for the analysis of microbial communities, the first step is the extraction of nucleic acids. It is worthy to consider that the use of different DNA/RNA extraction methods can lead to significant differences in terms of microbial community composition (Henderson et al., 2015). Several extraction procedures have been reported in the literature because the extraction protocol is linked to the downstream analyses and the equipment available. As a consequence, care should be taken when results from different studies that adopted different extraction methods to analyze samples of rumen content are compared (Henderson et al., 2015). Issues related to the nucleic acid extraction procedure also have to be faced when total RNA is extracted. A few studies have exploited the acid guanidinium-phenol-chloroform method (Li et al., 2016; Elekwachi et al., 2017), which was improved by BéraMaillet et al. (2009). More recently, Li et al. (2016) proposed a method based on liquid nitrogen grinding 
of whole ruminal solids followed by acid guanidiniumphenol-chloroform extraction with column purification (according to the method developed by Wang et al., 2011) for the analysis of microbial communities in steers.

Another crucial aspect to consider is the presence in rumen samples of PSC (e.g., tannins) that can hinder downstream analysis by PCR inhibition and forming complexes with nucleic acids (Wang et al., 2011; Henderson et al., 2015), thus requiring additional purification steps. The quality of extracted nucleic acids can be assessed by relative absorbance measurements (A260/230 nm and A260/280 nm). For most applications, ratios of $\sim 2.2(\mathrm{~A} 260 / 230 \mathrm{~nm})$ and $\sim 1.8$ to 2.0 (A260/280 nm for DNA and RNA, respectively) are considered optimal but cannot be reached with all the extraction and purification protocols (Henderson et al., 2015). The quality of extracted RNA can be assessed also using the RNA integrity number (Wang et al., 2011), which ranges from range from 1 (completely degraded) to 10 (intact).

Phylogenetic Markers of Rumen Microbiota. Small subunit rRNA genes, such as the 16S rRNA gene for prokaryotes and $18 \mathrm{~S}$ rRNA gene for eukaryotes, have been widely used for the taxonomic classification and as phylogenetic markers in microbial community structure analysis (Wang and Qian, 2009). The 16S rRNA gene contains 9 hypervariable regions (V1-V9), with different sequences according to the phylogenetic distance of microorganisms. This characteristic allows the identification of different taxonomic groups. The hypervariable regions are flanked by conserved regions. The conserved regions can be used to design universal primers for the amplification of the $16 \mathrm{~S}$ rRNA gene (or of specific hypervariable regions) from a wide range of microorganisms (Baker et al., 2003; Chakravorty et al., 2007). However, it is important to consider that it is not possible to identify a universal primer set with optimal performance for the microbial communities from different environments. Several authors targeted the $\mathrm{V} 1-\mathrm{V} 3$ regions and the $\mathrm{V} 3-\mathrm{V} 5$ regions for the characterization of rumen bacterial communities (Kim et al., 2017). Sets of specific primers that can be exploited in the characterization of the microbial communities in the rumen have been developed (Kim et al., 2017). Furthermore, for the characterization of bacterial or archaeal communities, specific primer sets are available (Henderson et al., 2015; Kim et al., 2017). Also, prokaryotic universal primers have been reported in the literature (Takahashi et al., 2014) and have been used to investigate the composition of microbial communities in rumen samples (Mannelli et al., 2018). Similar to $16 \mathrm{~S}$ rRNA for prokaryotes, the $18 \mathrm{~S}$ rRNA gene can be used as marker for fungi and protozoa (Edwards et al., 2017; Kim et al., 2017). However, several studies targeting anaerobic fungi adopted the internal transcribed spacer 1 region and the 28S rRNA gene, which allowed a better differentiation at low taxonomic levels (Edwards et al., 2017).

Study of Microbial Diversity and Function Using NGS Technologies. Next-generation sequencing provided new opportunities for the characterization of the microbial communities. Due to a continuous improvement of the NGS technologies and the related decrease of the sequencing costs, these strategies are becoming increasingly accessible and the amount of data produced is growing. Several studies have exploited the high-throughput of NGS to characterize bacterial, archaeal, fungal, and protozoal communities by sequencing phylogenetic markers and to shed light on the complex microbial processes in the rumen (Pitta et al., 2010; Fouts et al., 2012; Henderson et al., 2015; Kim et al., 2017). However, when phylogenetic markers are used to describe microbial communities it is crucial to consider that they are produced using PCR reaction, and therefore are subject to bias introduced during the amplification step (Firkins and Yu, 2015; Kim et al., 2017). The most common issues deal with lack of amplification with universal primers for certain microbial groups, variable amplification efficiency for different microorganisms, and formation of artifacts (Firkins and $\mathrm{Yu}, 2015$ ). Furthermore, the phylogenetic characterization of a microbial community does not allow direct reconstruction of its functional profile.

Another strategy that exploits the power of NGS for the description of microbial communities is metagenomics, which has been defined as the "analysis of genomic DNA from a whole community" (Gilbert and Dupont, 2011). Although the high-throughput sequencing of amplicon-based libraries of phylogenetic markers can give information about the microorganisms that are selected in the rumen, metagenomics also provides useful information on the presence of functional genes (Vincent et al., 2017). However, metagenomics does not allow discrimination of which pathways are active in a given condition. When the goal is to investigate the presence of active pathways in a given moment, high-throughput sequencing of total mRNA (i.e., metatranscriptomics) can be a suitable strategy (Vincent et al., 2017).

The strength of metagenomics and metatranscriptomics has recently been shown to provide useful information about the link between rumen microbiome and feed efficiency, and about the metabolic processes linked to methane production (Wallace et al., 2015; Li et al., 2018). Metagenomics has also been successfully 
used for functional screening of rumen communities and to describe the associated metabolic potential (Brulc et al., 2009).

Other powerful "omic" approaches that can be exploited for the investigation of the microbial activity in rumen samples involve the analysis of the proteins that are produced by the community (i.e., metraproteomics) or the analysis of the whole metabolic activity (i.e., metabolomic; Wallace et al., 2017). The combination of multiple strategies in a "multi-omics" approach can provide a complete view of the microbial community (Franzosa et al., 2015).

Platforms Available for NGS. Different NGS platforms are currently available for the characterization of microbial communities (Goodwin et al., 2016; Vincent et al., 2017). An overview of the throughput, sequencing errors and read lengths of different platforms has been recently reported by Goodwin et al. (2016). The first NGS platform available on the market was the 454 pyrosequencing. This technology, which was discontinued by Roche in 2016 (Goodwin et al., 2016; Vincent et al., 2017), has been used for the characterization of microbiomes in several environments, including the rumen (Fouts et al., 2012; Henderson et al., 2015; Kim et al., 2017). SOLiD sequencing has also been suggested as a suitable strategy for the characterization of microbiomes (Mitra et al., 2013). Among the technologies currently available on the market, Illumina platforms, particularly the Illumina MiSeq, are the most used for the taxonomic characterization of microbial communities. An alternative is represented by the Ion Torrent platforms, which now allow to obtain read lengths up to 600 bp (Goodwin et al., 2016). Recently, long read sequencing has been introduced, providing read of hundreds of kilobases in length, but with a high error rate compared with the short-read technologies (Goodwin et al., 2016).

Different workflows implemented in several bioinformatic tools are available to process phylogenetic, metagenomic, or metatranscriptomic data produced by NGS. A detailed overview of the strategies for the analysis of sequencing data is out of the scope of the present review, and only a brief discussion is reported. For a complete description of the aspects related to bioinformatic analysis for the characterization of microbiomes, the reader can refer to dedicated literature ( $\mathrm{Ju}$ and Zhang, 2015; Quince et al., 2017; Li et al., 2018). Quality-filtered data by high-throughput sequencing of phylogenetic markers can be clustered into operational taxonomic units, and taxonomic assignment of representative sequences for each operational taxonomic unit can then be performed (Ju and Zhang, 2015). The analysis of metagenomic and metatranscriptomic data is usually more computing-intensive and can involve several steps after the quality filtering: the removal of host sequences, the assembly of the reads into longer contigs, the gene prediction, and the assignment of a specific function to the predicted genes (i.e., annotation; Quince et al., 2017; Li et al., 2018).

\section{Rumen Microbiota Composition}

Ruminal bacteria are the most abundant members of rumen microbiota. They fermented ingested carbohydrates and lead to the production of VFA, $\mathrm{CO}_{2}$, and $\mathrm{H}_{2}$. Moreover, they produce newly synthesized microbial protein, lipids, and vitamins. The first-generation studies based on classical microbiology techniques focused on the metabolisms of the specific bacterial strains isolated from rumen contents, and depending on bacteria ability to degrade specific substrates, they were classified to different functional groups: cellulolytics, amylolytics, proteolytics, lipolytics, methanogens, saccharolytic, tanninolytic, pectinolytic, ureolytic, acetogenes, and acid utilizers (Choudhury et al., 2015). In fact, although some bacterial strains are able to degrade a specific substrate, some other strains can metabolize more than one substrate. This is the case of Prevotella ruminicola, Prevotella bryantii, Prevotella albensis, Prevotella brevis, Butyrivibrio fibrisolvens, and Fibrobacter succinogenes, which may ferment both structural and nonstructural carbohydrates; conversely, the genus Selenomonas and Streptococcus bovis are more represented in the rumen of animals fed more soluble carbohydrate diets, as they are electively starch- and sugar-degrading bacteria (Tajima et al., 2001; Ellison et al., 2017).

The new advances in molecular techniques allow to evaluate the predominance in the rumen content of certain bacterial groups and their possible interactions with the other members of the microbiome. Several studies reported that the most represented phyla in rumen content of adult animals are Bacteroidetes, Firmicutes, and Proteobacteria, accounting for more than $80 \%$ of total bacteria (Jami et al., 2013). The genus Prevotella has been indicated as one of the predominant members in the microbial community (Pitta et al., 2010; Morgavi et al., 2013). Henderson et al. (2015) reported that Prevotella, Butyrivibrio, Ruminococcus, and other unclassified members of Lachnospiraceae, Ruminococcaceae, Bacteroidales, and Clostridiales accounted for $67.1 \%$ in a pool of bacterial sequence data collected from different ruminant species, in 5 continents and fed different diets; $70 \%$ of these bacteria were not within a formally recognized genus. Member of $\mathrm{Fi}^{-}$ brobacter and Veillonellaceae allowed the communities from cattle and goats respectively to cluster separately from the communities described in other herbivore 
species (Henderson et al., 2015). Also, Nathani et al. (2015) reported that, regardless of diet, the most abundant bacterial genera in buffalo rumen content were Prevotella and Bacteroides, ranging from 10 to $50 \%$. These bacteria were present at higher percentages in the rumen liquid fraction, compared with the solid fraction. Similarly, Jewell et al. (2015) reported that the prevailing bacterial genera, identified by sequencing the $16 \mathrm{~S}$ rRNA gene, in the rumen content of dairy cows were Prevotella (40.15\%), Butyrivibrio (2.38\%), Ruminococcus $(2.35 \%)$, Coprococcus $(2.29 \%)$, and Succinoclasticum $(2.28 \%)$, whereas the less represented $(<1 \%$ of total bacterial community) phyla included members of the Spirochaetes, Fibrobacteres, Planctomycetes, and Verrucomicrobia. The total number of bacterial cells in the rumen seems to be around $10^{10}$ cells $/ \mathrm{mL}$ (Koike and Kobayashi, 2001; Morgavi et al., 2013) and more than 450 taxa have been reported (Fouts et al., 2012). Kong et al. (2010), investigating the microbiota of the rumen contents of cows fed different forages, found that members of Prevotella, Butyrivibrio, Lachnospiraceae, Pseudobutyrivibrio, and Ruminococcus were present in both the liquid and solid fraction, whereas bacteria of the genera Succiniclasticum, Anaerovorax, Succinivibrio, and Anaeroplasma were identified in the liquid fraction of the rumen; members of the genera Xylanibacter, Hallela, Lachnobacterium, Succiniclasticum, and Fibrobacter were present as loosely attached on particulates. Other genera, such as Papillibacter, Bulleidia, Anaerovorax, and Succinivibrio, were present as tightly attached to particles.

The ciliate protozoa can account for up to the $50 \%$ of ruminal microbial biomass (Choudhury et al., 2015). Although ruminants can live without the ciliate community in the rumen (defaunation), protozoa can play a pivotal role in rumen ecosystem: they live in symbiotic association with archaea, engulf organic matter particles and the bacteria, and seem to favor the activity of the consortium of bacteria operating fiber digestion (Newbold et al., 2015). Protozoa play an active role in fiber, carbohydrate, protein, and lipid digestion; they produce VFA (particularly acetate, butyrate) and $\mathrm{H}_{2}$ (Choudhury et al., 2015). Ciliate protozoa communities have been classified into 4 types: the A-type community, with Polyplastron multivesiculatum as the key species; the B-type community, with Epidinium ecaudatum and Eudiplodinium maggii as key species; the O-type community, which is composed only by species from Entodinium, Dasytricha, and Isotricha genera; and the K-type community, specific for cattle, with Elytroplastron bubali as the key species (Kittelmann and Janssen, 2011). Several studies reported that the protozoa of the genera Entodinium and Epidinium are dominant in the rumen microbial consortium. Henderson et al. (2015) reported that these genera accounted for the $54.7 \%$ of protozoal sequence data. Kittelmann and Janssen (2011) characterized the ciliate protozoa composition in the rumen of sheep, deer, and cattle and found that in deer and sheep the predominant genera were Epidinium and Eudiplodinium (accounting for more than $80 \%$ of total ciliate), whereas in cattle the predominant genera were Ostracodinium (81-86\% of total ciliate) and Polyplastron (7-11\% of total ciliate). Other observed genera were Entodinium, Anoplodinium-Diplodinium, Dasytricha, and Isotricha (Kittelmann and Janssen, 2011). However, it is worth mentioning that larger protozoa such as Epidinium or Polyplastron tended to be overrepresented by a pyrosequencing approach compared with microscopic enumeration (Newbold et al., 2015). Because the genome of ciliates contains a very high copy number of rRNA gene in the macronucleus, which may vary with life history, cell size, and growth of the cells, studies based on the rRNA gene copy number variation between and within ciliate species may make it difficult to infer the relative abundance of microbial eukaryotic cells in rumen samples. On the basis of this consideration, microscopic identification and counting is still the gold standard for analyzing ciliate protozoa in the rumen (Newbold et al., 2015).

Ruminal methanogenic archaea live in strict association with protozoa and bacteria and metabolize $\mathrm{H}_{2}$ and $\mathrm{CO}_{2}$ to produce methane (Choudhury et al., 2015). Henderson et al. (2015) reported that the dominant methanogen archaea in herbivores (either wild or domesticated) were Methanobrevibacter gottschalkii and Methanobrevibacter ruminantium, which accounted for $74 \%$ of all archaea, followed by the less represented Methanosphaera sp. and 2 Methanomassiliicoccaceae-affiliated groups, regardless of the geographical distribution, animal species, and diet. These results confirmed those reported by Snelling et al. (2014), who found that Methanobrevibacter, Methanosphaera, and Methanobacteria genera were dominant in the rumen of mature grazing sheep. Also, Kumar et al. (2015) found that the phylum Euryarchaeota with the genera Methanobrevibacter and Methanosphaera represented about 98\% of the archaeal community in lactating cows. Wang et al. (2016) reported that archaea contributed only 3 to $4 \%$ of the goat rumen microbiome and found that this population was less sensitive to animal aging and diet than bacteria.

The anaerobic fungi belong to the phylum of Neocallimastigomycota (Liggenstoffer et al., 2010). Although they are present in low numbers in the rumen content $\left(10^{6}\right.$ cells $/ \mathrm{mL}$ of rumen liquid), they play a major role in the degradation of dietary plant structural carbohydrates, thanks to their polysaccharide-degrading enzymatic pool (Krause et al., 2003). Kumar et al. (2015) 
found in the rumen content of dairy cows the known genera Casecomyces, Cyllamyces (which in primiparous cows accounted for up to $45 \%$ of total fungi), Orpinomyces, and other unidentified genera accounting for up to $75 \%$ of the total fungal community in cows fed different diets.

Interactions between different microbial populations for the utilization of nutrients can occur in rumen communities, as some metabolites produced by some microbes are the needed substrate for the metabolism of other microorganisms. Several studies have investigated the correlation between the members of the rumen community. Kumar et al. (2015) reported that bacteria of the family Prevotellaceae, of the genus Butyrivibrio, microorganisms close to the uncultured BS11, BF311 clones, and of the fungi belonging to Orpinomyces were not correlated with other genera; conversely, members of Prevotella, Bacteroidales, Paludibacter, Succinoclasticum, and members of Lachonspiraceae, Ruminococcus, and other Clostridia showed high co-occurrence with each other, with methanogens, and with fungi. Belanche et al. (2012) found a positive correlation between $\mathrm{H}_{2}$-producing microorganisms (bacteria, fungi, and protozoa) and $\mathrm{H}_{2}$-consuming microorganisms. This was further confirmed by Kittelmann et al. (2013), who found positive correlations between M. ruminantium and bacteria in the family Fibrobacteriaceae and between M. gottschalkii and bacteria of the family of Ruminococcaceae, indicating an association in which Fibrobacteriaceae and Ruminococcaceae produce substrates for rumen methanogens (formate and $\mathrm{H}_{2}$, respectively). Nathani et al. (2015) found that groups such as Fibrobacter and Firmicutes (within both fibrolytic bacterial are described) correlated positively with Spirochaetes, probably because the Spirochaetes decarboxylated the succinate formed by Fibrobacter, and correlated negatively with the Bacteroidetes. Pitta et al. (2010) reported a positive association between Prevotella and Troponema, and between Ruminococcus and Tannerella in the rumen of wheat hay-fed steers. Troponema is known as a soluble-fiber-degrading group (Ziolecki, 1979), whereas Ruminococcus is a cellulolytic group that can account for $10^{6}$ cells $/ \mathrm{mL}$ of rumen content (Koike and Kobayashi, 2001). The activity of both Troponema and Ruminococcus can be considered as supportive for Prevotella and Tannerella, which have as elective substrate carbohydrates (Wallace, 2008). Kittelmann et al. (2013) reported significant correlations also between ciliate protozoa and fungi (i.e., negative correlation between Isotricha and anaerobic fungi of the BlackRhino group and positive correlation between Entodinium and Neocallimastix 1-group), although the ecological meaning of these associations remains to be unraveled.
Overall, the current information about rumen microbiota composition suggests that a "core bacterial microbiome" exists, as defined by Henderson et al. (2015). However, age (Wang et al., 2016), animal physiological state (Dieho et al., 2017), and feeding regimen (Belanche et al., 2012) can actively modulate the composition of ruminal microbiota. Nevertheless, data on the relative abundance of the members of ruminal microbial community should be taken with caution because different analytical techniques can lead to conflicting results (Weimer, 2015).

\section{DIETARY POLYPHENOLS}

The term PP refers to a wide class of plant secondary metabolites with a phenolic moiety, bearing at least one hydroxyl substituent. The PP can range from simple phenolics (e.g., ellagic and gallic acids), to dimeric or oligomeric compounds (e.g., procyanidins, lignans), or to polymeric compounds with high molecular weight (e.g., tannins; Bravo, 1998). They can occur conjugated mostly with sugar residues (glycosides), but also as a single compound with carboxylic and organic acids, amines, and lipids (aglycones; Bravo, 1998). Polyphenols are classified as flavonoids, the most common group of phenolics, or as nonflavonoids. Flavonoids are in general based on 2 aromatic rings linked by a bridge constituted by 3 -carbon, with a $\mathrm{C}_{6}{ }^{-} \mathrm{C}_{3}-\mathrm{C}_{6}$ basic structure. The 3-carbon bridge usually forms an oxygenated heterocycle, resulting in a 3-ring structure formed of 15 carbons. According to the degree of oxidation of the heterocycle structure, the kind of sugar residue, and the degree of polymerization, flavonoids can be classified in flavonols, flavones, isoflavones, flavan-3-ols (or flavanols), flavanones, and anthocyanidins (Bravo, 1998). The polymerization of flavan-3-ols leads to the formation of condensed tannins (CT; Bravo, 1998). The degree of polymerization of CT can account for 50 or more units with a molecular weight of up to 30,000 Da. Usually, in the literature only oligomeric proanthocyanidins are reported (with a molecular weight around $5,000 \mathrm{Da}$ ) because the high polymeric compounds are difficult to analyze (Schofield et al., 2001). High molecular weight CT are insoluble. On the basis of differences in the hydroxyl substitution patterns and in the relative stereochemistry of the C-2 and C-3 substituents in the aromatic ring, it is possible to obtain several products of polymerization of flavan-3-ols: catechin, epicatechin gallate, epigallocatechin, epigallocatechin gallate, proanthocyanidins, theaflavins, and thearubigins. Procyanidins are a special class of proanthocyanidins derived by the polymerization of epicathechin units.

Among nonflavonoid compounds, there are phenolic acids, hydrolyzable tannins (HT), and stilbenes. Pheno- 
lic acids derive from benzoic acid and hydroxycinnamic acid and they can be simple phenols $\left(\mathrm{C}_{6}\right.$ structure, such as phenol or thymol) or with a $\mathrm{C}_{6}-\mathrm{C}_{1}$ structure, such as gallic or vanillic acid (Bravo, 1998). Hydrolyzable tannins are classified as gallotannins and ellagitannins. In the first case, the core of HT is a glucose esterified to gallic acid, whereas in the second case glucose is esterified to both hexahydroxydiphenic acid (also named ellagic acid) and gallic acid. These tannins are hydrolyzable with acid, alkali, and hot water, and by enzymatic action.

The PP have been largely studied for their biological role in plants, antioxidant activity and health-promoting effects in humans (Shahidi and Ambigaipalan, 2015), and their effects on animal nutrition and production (Makkar, 2003; Patra and Saxena, 2011).

The occurrence of PP in herbivores' diets is very common, especially for grazing animals. Fraisse et al. (2007) determined the phenolic fractions (phenolic acids, flavonoids, and total phenols) over 43 botanical species of the pasture at 3 stages of growth and detected about 170 different phenolic compounds consisting of dihydroxycinnamic derivatives and flavonoids. The same study estimated that a grazing cow could consume up to $500 \mathrm{~g}$ per day of PP. Most legume forages present in swards contain $\mathrm{PP}$, for example, sulla (Hedysarum coronarium; Priolo et al., 2005), birdsfoot trefoil (Lotus corniculatus), big trefoil (Lotus pedunculatus; Barry and McNabb, 1999), vetch (Vicia sativa; Cabiddu et al., 2010), sainfoin (Onobrychis coronarium), and sericea (Lespedeza cuneata; Puchala et al., 2005). In many regions, considering the competition between human being and livestock farming for the use of lands and water, herbivores graze wild bushes rich in PSC (Landau et al., 2000). Similarly, in dry areas, seeding low-water-consuming crops is a strategy for overcoming water scarcity and supporting livestock farming. This is the case for some pasture species such as safflower (Carthamus tinctorius; Landau et al., 2005) or chicory (Cichorium intybus; Molle et al., 2008), which are rich in PP. In dry areas of the Mediterranean, sheep and goats browse tree leaves rich in tannins such as acacia (Acacia cyanophylla) or the argan tree (Argania spinosa) or are fed local marginal feeding resources rich in tannins, such as carob (Ceratonia siliqua) or pods (Vasta et al., 2008).

The use of agro-industry by-products and food waste is another important part of the global strategy to reduce the environmental impact of livestock production and the competition for arable land between food and feed products (Makkar and Ankers, 2014; Flachowsky et al., 2017). Agro-industry by-products may contain considerable amounts of PSC, including different kind of PP, such as tannins or flavonoids (Makkar, 2003; Vasta and Luciano, 2011).

Due to the relevant effects of PP on animal nutrition and performance (see below), a large number studies have been conducted by testing tannin-rich feed or pure tannin extracts (such as quebracho tannins, chestnut tannins, tannic acid, gallic acid) or other phenolic compounds (e.g., quercetin, a flavonoid) both in vitro and in vivo. In the present manuscript, for each study quoted, it is specified what type of PP has been used.

\section{Effects of Dietary PP on Nutrition and Performance in Dairy Ruminants}

Several studies are available in the literature about the effects of PP on ruminant nutrition. In particular, tannins have anti-bloat properties (Lees, 1992), improve nitrogen utilization (Patra and Saxena, 2011), reduce methane production (Kumar et al., 2014), have anti-helmintic effect (Min et al., 2003), interfere with the $\mathrm{BH}$ of fatty acids, and consequently, contribute to modulate the fatty acid profile of ruminant products (Buccioni et al., 2011; Toral et al., 2011).

Data on the effects of dietary PP on ruminant nutrition and performance have been extensively reviewed in the past, especially in the case of tannins (both $\mathrm{CT}$ and $\mathrm{HT}$ ), by considering either the addition of purified substances or the natural PP present in forages and concentrate feed ingredients (Makkar, 2003; Min et al., 2003; Waghorn, 2008).

Hence, in the present paragraph only a brief summary of the main effects of PP on dairy ruminant nutrition and performance is reported, remanding to the above reported reviews for a more complete discussion. Where the species is not reported, the effects must be considered for ruminants in general.

According to Frutos et al. (2004), the total amount of dietary PP may affect the voluntary feed intake. Indeed, high doses of tannins (both $\mathrm{CT}$ and $\mathrm{HT}$ ) significantly reduced the voluntary feed intake and animal performance, if compared with low or medium doses. This was probably due to the reduction of palatability of diets caused by the astringent activity of tannins (Patra and Saxena, 2011). Although differences have been reported according to the nature of tannins, in dairy sheep practice doses are usually considered between 20 and $40 \mathrm{~g}$ per head and day (Toral et al., 2011; Buccioni et al., 2015a,b).

Regarding milk production, contrasting results are reported in the literature. In most cases, no effects have been reported, irrespective of the type of $\mathrm{PP}$ and of the use of pure extracts or agro-industry by-products in both dairy cows (Dschaak et al., 2011; Moate et al., 
2014) and dairy sheep (Abbeddou et al., 2011; Toral et al., 2011; Buccioni et al., 2015a). On the other hand, positive effects of tannin-rich plants on milk yield and urea content have been well documented in the literature for dairy ewes (Molle et al., 2008). Positive results on milk yield have been also reported in grazing ewes supplemented with chestnut tannins (Buccioni et al., 2015b).

Overall, although some contrasting results are still present in the literature, mainly due to the heterogeneity of the composition of dietary PP, it is possible to state that low to moderate amounts of tannins (from 1 to $2 \%$ of total DMI) in the diet of dairy ruminants did not result in any detrimental effect on animal performance.

\section{Effect of PP on Rumen Microbiota}

Early studies on the effects of dietary PP focused mostly on the effect of tannins on ruminants' performance and feed utilization efficiency: in fact, tannins have been shown to possess both detrimental and favorable effects, depending on the diet composition, the animal species, the tannin source, and the level of their inclusion in the diet (Frutos et al., 2004; Waghorn, 2008). Tannins might have a toxic effect on some rumen microbes, by altering the permeability of membranes (Frutos et al., 2004). Moreover, tannins may inhibit the enzyme activity of ruminal microorganisms (Jones et al., 1994). However, the toxic effect is strongly dependent on the dose and the nature of tannins as well as the bacteria species. For instance, an in vitro study demonstrated that the activity of proanthocyanidin against Clostridium aminophilum, B. fibrisolvens, and Clostridium proteoclasticum depended to their chemical structure, whereas the growth of Ruminococcus albus and Peptostreptococcus anaerobius was strongly affected, regardless of the fraction of proanthocyanidin adopted or the dose applied (Sivakumaran et al., 2004). Condensed tannins have a direct inhibitory effect on hemicellulases, endoglucanase, and proteolytic enzymes of several rumen microbes such as $F$. succinogenes, $B$. fibrisolvens, Ruminobacter amylophilus, and S. bovis (Jones et al., 1994; Bhat et al., 1998). Conversely, P. ruminicola is able to counteract the negative effect of tannins by producing protective extracellular material (Jones et al., 1994). Moreover, in the case of HT, several microorganisms, belonging to both bacteria and fungi, are able to completely degrade gallic acid (the main component of HT) to acetate and butyrate (Bhat et al., 1998). Since these observations, several studies were conducted to assess the effect of tannins and other $\mathrm{PP}$ on ruminal microorganisms.
The new generation of molecular techniques is opening a window into the effect of $\mathrm{PP}$ on rumen microbiota. It has been reported that supplementing heifers a mixture of PP (mostly flavonoids) and essential oil, compared with the control animals, increased many taxa of the Bacteroidetes, Firmicutes, and Tenericutes and reduced the phyla Proteobacteria, Verrucomicrobia, and Actinobacteria (based on classification of the 16S rRNA gene; De Nardi et al., 2016). Vasta et al. (2010) found that supplementing lambs quebracho tannins (which are CT) had a strong effect on ruminal microbiota, as the microbial community (determined by T-RFLP on bacterial $16 \mathrm{~S}$ rRNA gene) of rumen contents of animals receiving or not the supplement clustered separately (Vasta and Bessa, 2012). A specific interest has also been devoted to the effect of $\mathrm{PP}$ on the metabolism of rumen microbes, especially with regard to ruminal $\mathrm{BH}$, methane production, and nitrogen utilization.

\section{Effect of PP on the Microbiota Operating the $\mathrm{BH}$ of Fatty Acids}

The $\mathrm{BH}$ is the progressive isomerization and saturation of dietary UFA performed by ruminal microorganisms. The UFA present in the diet of ruminants are mainly linoleic acid ( cis-9, cis-12 C18:2; LA), $\alpha$-linolenic acid (cis-9, cis-12, cis-15 C18:3; LNA) and, to a minor extent, MUFA, such as oleic acid (cis-9 C18:1). The $\mathrm{BH}$ process starts with the lipolysis of the dietary triglycerides, phospholipids, and glycolipids to obtain free UFA. Then, most of the UFA released by lipolysis are subjected to sequential steps of isomerization and saturation to obtain stearic acid (C18:0; SA ) as the end point. During the process, according to the initial UFA and to the biochemical pathway activated by rumen microbes, many positional and geometrical isomers of C18:3, C18:2, and C18:1 fatty acids may be produced (Shingfield et al., 2010). In the first steps of BH, a bacterial isomerase produces conjugated isomers of LNA and LA, mostly associated with the isomerization of cis-12 double bound. In the next steps, the most common BH pathway for both LA and LNA produces vaccenic acid (trans-11 C18:1; VA) as the main monounsaturated intermediate. However, specific rumen conditions, associated with several variation factors, may result in shifts of the biochemical pathways associated with rumen $\mathrm{BH}$ processes. The main variation factors able to affect rumen $\mathrm{BH}$ pathways are animal species, diet composition (i.e., amount and type of forage, amount of starch and its rumen degradability), rumen $\mathrm{pH}$, passage rate of rumen digesta, amount and type of dietary fat supplementation, and specific dietary ingredients able 
to interact with rumen microbes, including some PSC (Shingfield et al., 2010).

The first step of the $\mathrm{BH}$ process, lipolysis, is mainly related to the presence of lipases produced by a restricted number of bacteria. The best-known bacterium able to efficiently produce extracellular lipases is Anaerovibrio lipolytica. However, lipolytic activity has been reported also for different species of the genus Butyrivibrio and, more recently, for rumen bacteria belonging to the Clostridium, Propionibacterium, Staphylococcus, and Selenomonas genera and for a Pseudomonas aeruginosa strain (Unni et al., 2016; Enjalbert et al., 2017).

With regard to the further steps of $\mathrm{BH}$ after lipolysis, pioneer studies indicated B. fibrisolvens as responsible for the BH (Kepler and Tove, 1967). Subsequently, other bacteria were shown to participate in the BH such as Butyrivibrio hungatei (van de Vossenberg and Joblin, 2003), strains of Clostridium (Wallace et al., 2006; Peng et al., 2007), Propionibacterium (Rainio et al., 2002), and Eubacterium (Verhulst et al., 1986). More recently, the application of DGGE technique to the study of the rumen microbiota composition from cows fed increasing amounts of fish oil revealed that as yet uncultured bacteria phylogenetically classified as Prevotella, Lachnospiraceae incertae sedis, and unclassified Bacteroidales, Clostridiales, and Ruminococcaceae may play a predominant role in ruminal BH (Huws et al., 2011). These results have been subsequently confirmed by studies based on NGS approaches (Toral et al., 2012; Petri et al., 2014; Bainbridge et al., 2016). Toral et al. (2012) in dairy sheep, Petri et al. (2014) in steers, and Bainbridge et al. (2016) in dairy cows did not find any correlation between the relative abundance of members of the genus Butyrivibrio with the intermediate and final products of $\mathrm{BH}$. On the contrary, similar to Huws et al. (2011), they reported significant correlations between $\mathrm{BH}$ products and the relative abundance of as yet uncultured Lachnospiraceae or bacteria belonging to Quinella genera (Toral et al., 2012), Flavobacterium sp., Anerophaga, Fibrobacter, Guggenheimella, Paludibacter, Pseudozobellia (Petri et al., 2014), and Acetobacter (Bainbridge et al., 2016).

With regard to protozoa, it seems to be unlikely that they contribute to $\mathrm{BH}$ through their enzymatic pool; instead they favor the outflow of $\mathrm{BH}$ intermediates to the intestine, as they engulf the bacteria that operate the BH (Lourenço et al., 2010).

The hypothesis that dietary PP could alter the activity of the ruminal microorganisms responsible for $\mathrm{BH}$ was first formulated by Priolo et al. (2005), as they observed that the meat of animals receiving sulla (H. coronarium, a CT-rich legume) contained greater proportion of LNA compared with the meat of animals receiving sulla plus polyethylene glycol (a tanning-binding agent) supplementation. In fact, Jones et al. (1994) found that the tannins present in sainfoin inhibited the in vitro growth and caused morphological changes of B. fibrisolvens A38. Subsequently, several studies confirmed that the inclusion of tannins into animals' diet (Vasta et al., 2009a) or into in vitro systems (Khiaosa-Ard et al., 2009; Vasta et al., 2009b; Buccioni et al., 2011) led to the accumulation of VA and to a reduction of SA compared with PP-free control treatments. These results suggested that PP could affect in a different manner those bacteria responsible for the formation of VA from LA and LNA and the bacteria that convert the VA into SA.

Table 1 summarizes the results obtained in different studies on the effect of $\mathrm{PP}$ on the $\mathrm{BH}$ and ruminal microorganisms. In the table, both in vitro and in vivo studies were reported, selecting those studies where pure PP or extracts have been adopted. The major part of the studies dealt with HT or CT and only one study was focused on nontannic PP (papaya extracts, Jafari et al., 2016).

In general, in vitro studies consistently obtained a negative effect of $\mathrm{PP}$ on SA accumulation in rumen digesta and an increase of VA and rumenic acid (cis-9, trans-11 C18:2; RA), regardless of the type of PP considered (Table 1). However, in the same studies, analysis of the microbiota composition did not provide clear indications about which changes in bacteria population are responsible for the effects on rumen BH. Ishlak et al. (2015) examined in continuous culture systems the effect of the inclusion of quebracho tannins on $\mathrm{BH}$ pathways and on selected bacteria species by individual species-specific qPCR. Results showed that quebracho tannins increased the accumulation of RA and, accordingly, the abundance of VA-forming bacteria of the genus Butyrivibrio. At the same time, quebracho tannins did not affect the abundance of A. lipolytica and Butyrivibrio species associated with SA production. Jafari et al. (2016) reported that the in vitro incubation of rumen content with PP extracts from papaya did not influence the genus Burtyrivibrio and depressed the ciliate protozoa population compared with PP-free treatments. At the same time, ruminal $\mathrm{BH}$ process of LA and LNA was depressed (Table 1). Also in this case, the relative abundance of total bacteria, total methanogens, B. fibrisolvens, and total protozoa was assessed by qPCR approach. Data about the effect of pure nontannic $\mathrm{PP}$ on $\mathrm{BH}$ and rumen microbiota composition are still scarce. However, some indications may be obtained by considering results obtained in studies adopting agro-industry by-products such as those from the olive oil industry. In particular, the use of olive pomace 
Table 1. The effect of polyphenols on ruminal microorganism abundance, on the biohydrogenation (BH) of dietary PUFA, and on the content of individual fatty acids involved in the $\mathrm{BH}$ process

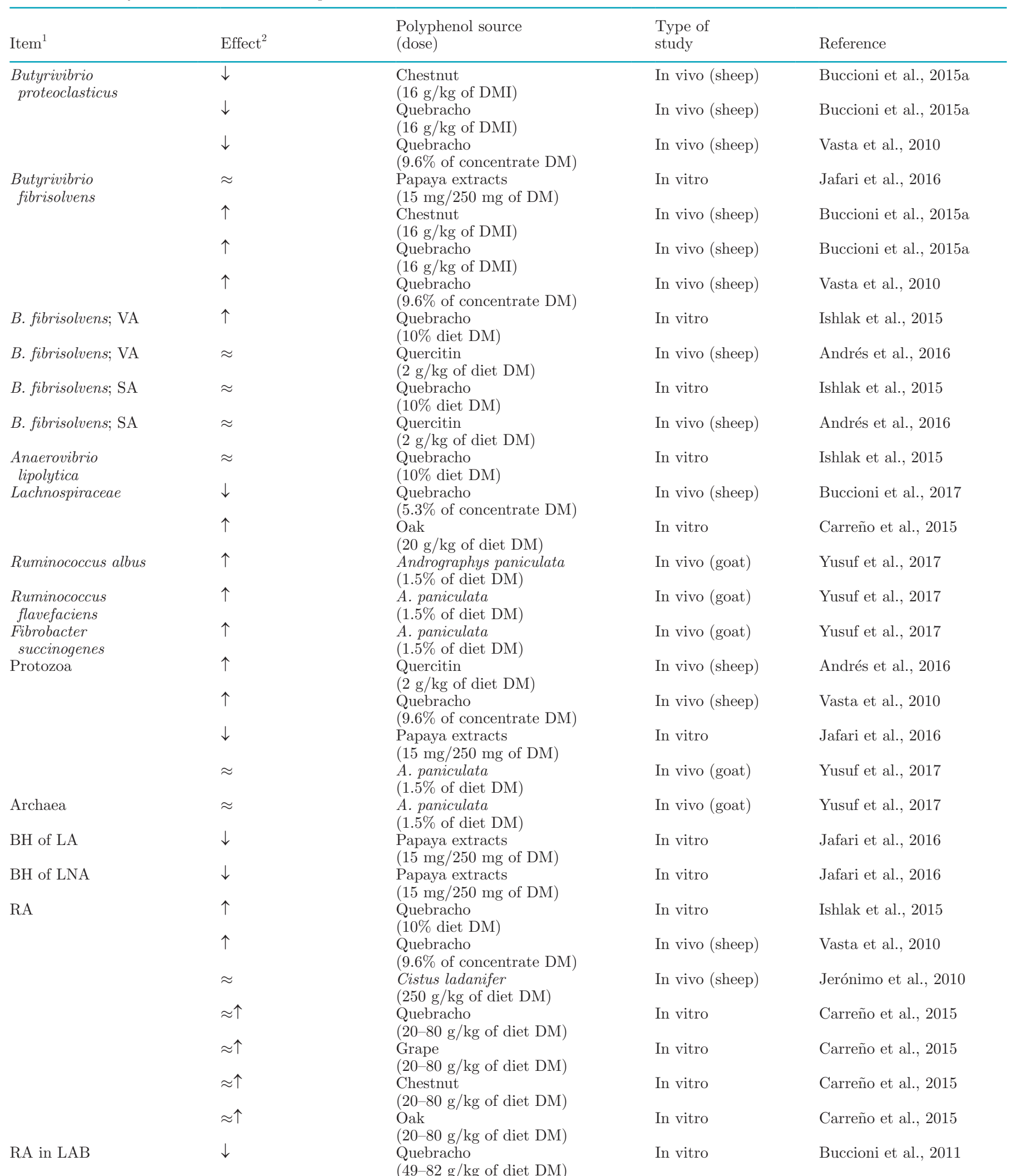


Table 1 (Continued). The effect of polyphenols on ruminal microorganism abundance, on the biohydrogenation (BH) of dietary PUFA, and on the content of individual fatty acids involved in the $\mathrm{BH}$ process

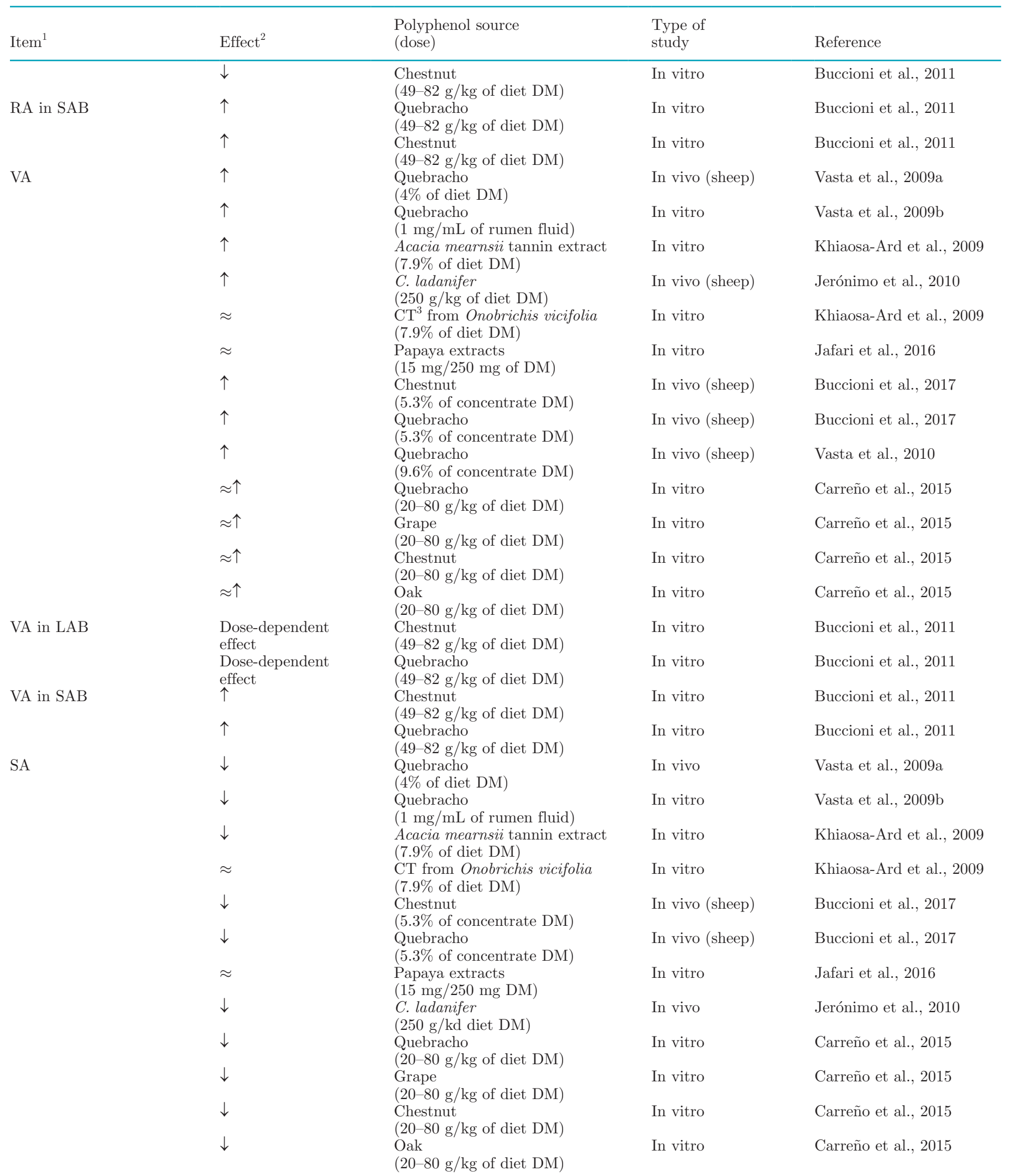


Table 1 (Continued). The effect of polyphenols on ruminal microorganism abundance, on the biohydrogenation (BH) of dietary PUFA, and on the content of individual fatty acids involved in the $\mathrm{BH}$ process

\begin{tabular}{|c|c|c|c|c|}
\hline Item $^{1}$ & Effect $^{2}$ & $\begin{array}{l}\text { Polyphenol source } \\
\text { (dose) }\end{array}$ & $\begin{array}{l}\text { Type of } \\
\text { study }\end{array}$ & Reference \\
\hline $\mathrm{SA}$ in $\mathrm{SAB}$ & $\downarrow$ & $\begin{array}{l}\text { Quebracho } \\
(49-82 \mathrm{~g} / \mathrm{kg} \text { of diet } \mathrm{DM})\end{array}$ & In vitro & Buccioni et al., 2011 \\
\hline $\mathrm{SA}$ in $\mathrm{LAB}$ & $\downarrow$ & $\begin{array}{l}\text { Quebracho } \\
(49-82 \mathrm{~g} / \mathrm{kg} \text { of diet } \mathrm{DM})\end{array}$ & In vitro & Buccioni et al., 2011 \\
\hline
\end{tabular}

${ }^{1} \mathrm{VA}=$ vaccenic acid; $\mathrm{SA}=$ stearic acid; $\mathrm{LA}=$ linoleic acid; $\mathrm{LNA}=$ linolenic acid; $\mathrm{RA}=$ rumenic acid; LAB = liquid-associated bacteria; $\mathrm{SAB}$ $=$ solid-associated bacteria.

${ }^{2}$ The effects $(\downarrow=$ decrease $\uparrow=$ increase; $\approx=$ unchanged) of polyphenols are evaluated in comparison to control treatments (i.e., diets or feed not containing polyphenols).

${ }^{3} \mathrm{CT}=$ condensed tannins.

has been tested in both in vitro and in vivo studies (Pallara et al., 2014). A modulating effect on rumen $\mathrm{BH}$ has been reported for stoned olive pomace rich in olive PP (aglycone derivatives of native secoiridoid glucosides, namely oleuropein, dimethyl oleuropein, and ligstroside) in an in vitro study (Pallara et al., 2014). Adopting a DGGE approach aimed at characterizing the microbial community, the study revealed that PP from stoned olive pomace altered the relative abundance of Butyrivibrio proteoclasticus, Neisseria weaveri, $R$. amylophilus, and other unclassified bacteria related to members of the Lachnospiraceae and Pasteurellaceae families. At the same time, an accumulation of transC18:1 fatty acids in the rumen liquor was detected (Pallara et al., 2014). An association between dietary PP (in this case HT from oak) and Lachnospiraceae family was also reported by an in vitro study adopting a T-RFLP approach for the analysis of bacterial $16 \mathrm{~S}$ rRNA genes (Carreño et al., 2015). In the same study, oak HT were associated with reduction of SA, as a consequence of an accumulation of VA, especially at the highest doses of oak tannins (Carreño et al., 2015).

Buccioni et al. (2011) reported, in an in vitro system, a different pattern of $\mathrm{BH}$ intermediates between $\mathrm{SAB}$ and $\mathrm{LAB}$ inoculated or not with chestnut or quebracho tannins. The authors supposed that the LAB could be more sensitive to tannins than the $\mathrm{SAB}$, or that the efficacy of quebracho or chestnut tannins was higher in the liquid fraction rather than in the solid fraction, thus being more detrimental to the LAB (Buccioni et al., 2011). Also in this case, the effect of both chestnut and quebracho tannins resulted in a decrease of SA and an increase of VA. However, the LAB and SAB have been shown to participate in the $\mathrm{BH}$ process in a different manner as the SAB contained more BH intermediate and lower SA compared with LAB (Bessa et al.,
2009; Buccioni et al., 2011). This could be partly due to the difference in the biodiversity of SAB populations if compared with LAB ones or to those loosely attached to particulates (Kong et al., 2010).

In vivo studies evaluating the effect of dietary $\mathrm{PP}$ on both rumen $\mathrm{BH}$ of UFA and on composition of the rumen microbiota are mainly related to the use of HT or CT and using small ruminants as animal models (Table 1). The general effect of HT and CT on BH process is quite consistent with results observed in in vitro studies: an increase of $\mathrm{BH}$ intermediates (especially VA) at the expense of SA, which decreased (Table 1). With regard to the effects on the composition of rumen microbiota, the major part of the studies confirmed that the bacteria traditionally associated with rumen $\mathrm{BH}$ of dietary lipids (such as members of the genus Butyrivibrio) are only in part involved in the response to tannin challenge. As reported by several papers that adopted different techniques to characterize microbiota of rumen digesta, likely, other microorganisms belonging to different genera and families are more involved in the process (Buccioni et al., 2017).

Buccioni et al. (2015a) reported that feeding ewes a diet supplemented with quebracho tannins (as source of CT) or chestnut tannins (as source of HT) increased the ruminal relative abundance of $B$. fibrisolvens and reduced $B$. proteoclasticus compared with control animals, and this effect was more evident with quebracho tannins. This result is consistent also with Vasta et al. (2010) who reported that supplementing lambs with quebracho tannins depressed the ruminal population of $B$. proteoclasticus, whereas it increased the relative abundance of $B$. fibrisolvens in the rumen, compared with the rumen content of lambs not receiving tannins. In both cases, quantitation of total and the relative abundance of B. fibrisolvens and B. proteoclasticus were 
measured by qPCR analysis, using $16 \mathrm{~S}$ rRNA genetargeted primer sets (Vasta et al., 2010; Buccioni et al., 2015a).

In a recent study with 3 groups of lactating ewes receiving a control diet supplemented or not with chestnut or quebracho tannins, ruminal $\mathrm{BH}$ was hampered by tannin supplementation (Buccioni et al., 2017). Also in this case, the effect on $\mathrm{BH}$ seemed to be related to a strong inhibition of the last step of the $\mathrm{BH}$ (from VA to SA), especially in the case of the diet supplemented with quebracho tannins. With regard to the microbiota composition of rumen digesta, differences were detected according to the type of tannin adopted. The Butyrivibrio communities of the chestnut-receiving animals were significantly different from the communities observed in the rumen of the other 2 groups of animals. According to the DGGE mapping of the Butyrivibrio group, 7 bands were not present in the samples deriving from animals supplemented with quebracho and these bands were found to be highly related to the Lachnospiraceae family (Buccioni et al., 2017). The phylogenetic analysis of the rumen content from tannin-supplemented ewes revealed a close association between bacterial species belonging to genera Hungatella, Ruminococcus, and Eubacterium and to unclassified Lachnospiraceae and the fatty acids involved in the BH (LA, LNA, RA, and VA; Buccioni et al., 2017). These results confirmed what was previously reported by Huws et al. (2011), who adopted the same DGGE approach to characterize the microbiota composition of rumen digesta in crossbred steers. Also, uncultured Lachnospiraceae were associated with SA, suggesting that $B$. proteoclasticus is not the only bacterial species able to convert UFA to SA, at least in the presence of tannins (Buccioni et al., 2017).

The dynamics of changes in microbial community responsible for the $\mathrm{BH}$ in response to $\mathrm{PP}$ appear to be quite complex, as the disappearance of PP-sensitive microorganisms could be counterbalanced by the prevailing of PP-tolerant ones. Recently, Costa et al. (2018) suggested that CT have a stronger inhibitory action on rumen microbiota than HT, resulting in a general inhibition of BH and accumulation of C18 PUFA. Conversely, $\mathrm{HT}$ are able to modulate $\mathrm{BH}$, resulting in a higher accumulation of trans-C18:1 fatty acids in the rumen, if compared with CT. High doses of mimosa CT in the diet of rumen-fistulated ewes, in fact, resulted in the reduction of rumen fermentative activity and abundance of gram-positive specialized fibrolytic bacteria (F. succinogenes, R. albus, Ruminococcus flavefaciens, and $B$. proteoclasticus) as well as an occasional inhibition of $\mathrm{BH}$, in comparison to the diet supplemented with the same doses of chestnut tannins (Costa et al.,
2018). Interestingly, in the same experiment, the use of chestnut tannins was associated with an accumulation of trans-C18:1 fatty acids, suggesting a possible adaptive strategy of rumen bacteria to counteract the toxicity of the tannins (Costa et al., 2018).

A different pattern of rumen $\mathrm{BH}$ has been observed when dietary sources of nontannic PP, such as olive pomace or olive crude concentrate obtained from olive oil wastewater, have been adopted in the diet of dairy ewes. In 2 recent experiments, olive PP, mainly composed by oleuropein, dimethyl oleuropein, verbascoside, and ligstroside, were included in the diet of dairy ewes to evaluate the effects on rumen BH of dietary UFA and on rumen microbiota composition (Cappucci et al., 2018; Mannelli et al., 2018). In both cases, the extent of rumen $\mathrm{BH}$ of LA and LNA was reduced; however, the pattern of the fatty acids involved in the $\mathrm{BH}$ process was different from the pattern observed in the in vivo trials adopting $\mathrm{CT}$ or $\mathrm{HT}$. When olive $\mathrm{PP}$ were included in the diet of dairy ewes, LA and LNA content in rumen digesta was higher than that observed in the rumen from ewes fed the control diet. At the same time, the content of SA significantly decreased along with the content of intermediates of $\mathrm{BH}$. This pattern, obtained in both experiments, with different by-products containing the same kind of PP (although at different concentrations) suggested that olive PP might interact with rumen $\mathrm{BH}$ by affecting the first step of $\mathrm{BH}$. The analysis of the microbiota composition from the study of Mannelli et al. (2018) provided an indirect confirmation to this hypothesis. In this study, in fact, the microbiota composition of individual rumen digesta samples, from dairy ewes fed a control diet or a diet supplemented with 2 kind of olive oil pomace was analyzed by adopting the Illumina MiSeq platform (Mannelli et al., 2018). Results showed that the relative abundance of Anaerostipes, Anaerovibrio, Anaeroplasma, Desulfobulbus, and Sphaerochaeta genera was influenced by the inclusion of olive oil pomace in the diet. In particular, Anaerovibrio was negatively correlated with LNA content in the rumen digesta, suggesting that olive PP could affect the first step of the $\mathrm{BH}$ process, by decreasing the relative abundance of $A$. lipolytica and, in turn, the rate of lipolysis of dietary lipids.

The role of PP in the lipolysis of dietary lipids has been previously investigated in specific forage plants. Cabiddu et al. (2010) have found that tannic PP and protein-bound phenols reduced ruminal fatty acid lipolysis and BH. Lee et al. (2010) suggested that a reduced lipolysis in the presence of PP could be due to an inclusion of lipids within protein-phenol complexes, thus making the substrate unavailable to lipolytic en- 
INVITED REVIEW: DIETARY POLYPHENOLS AND RUMEN MICROBIOTA

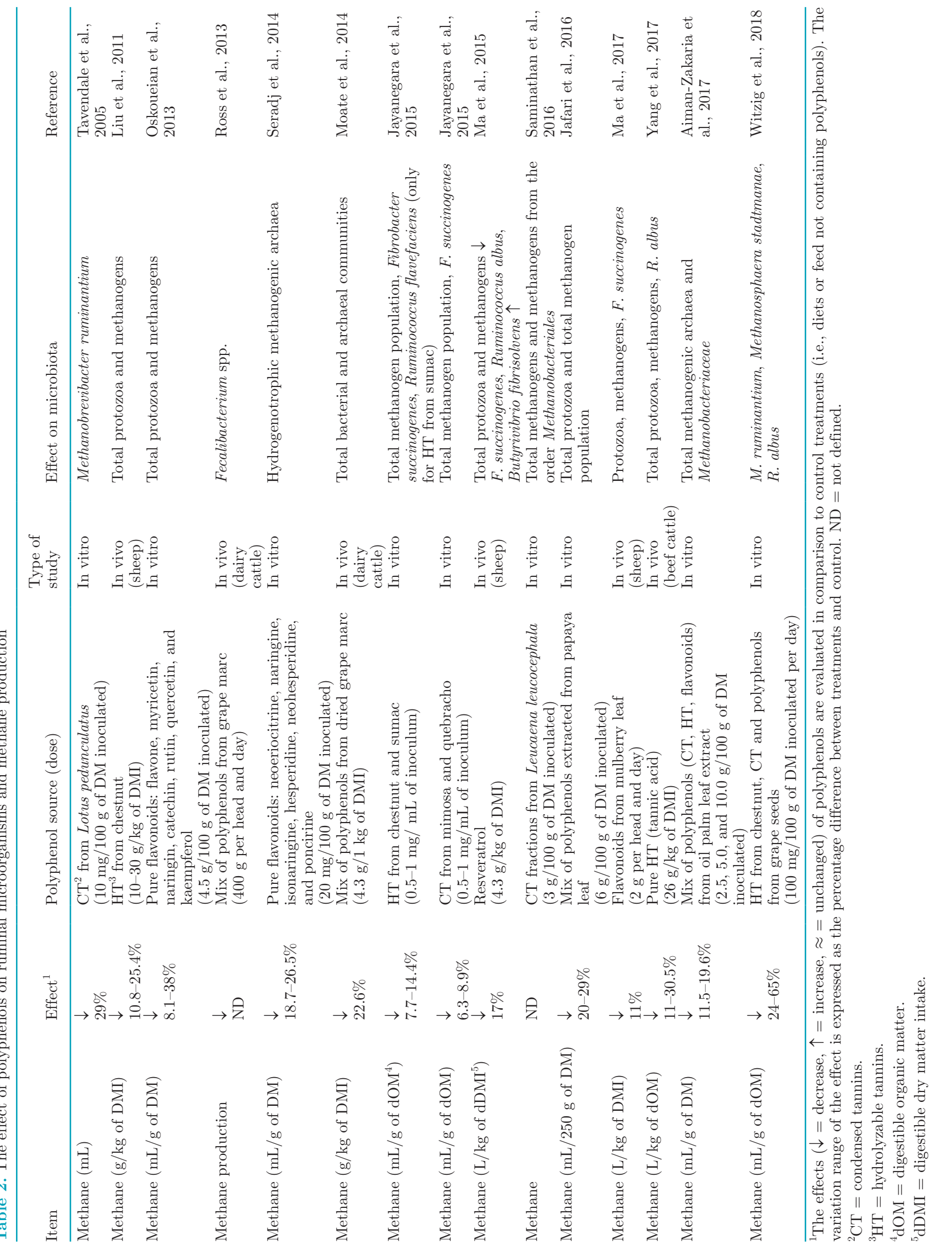




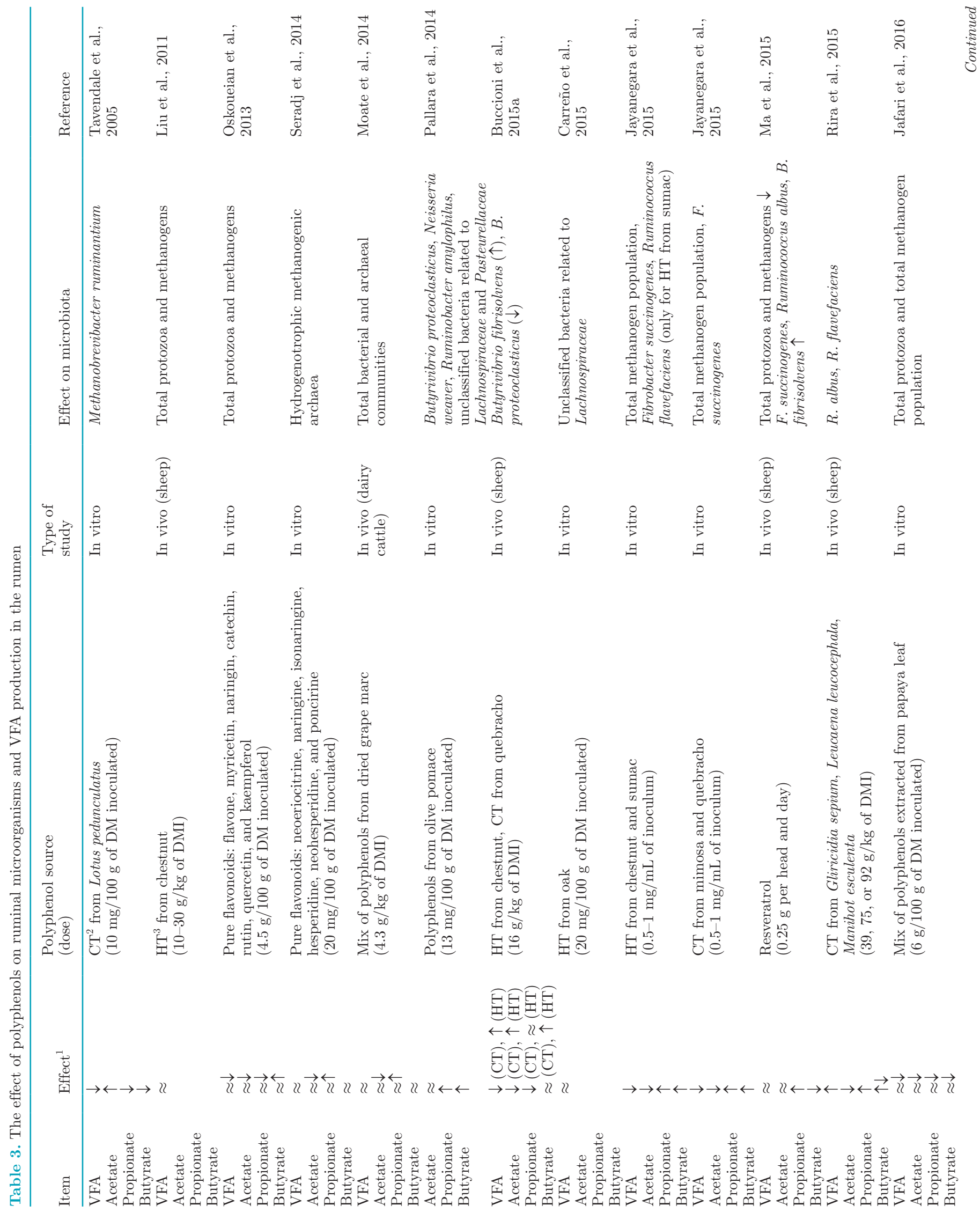


zymes. Nevertheless, the extent of lipolysis as affected by PP deserves to be further investigated.

\section{Effect of PP on the Microbiota Responsible for Fiber Digestion and Methane Production}

The cultivable bacteria mostly involved in fiber digestion are $F$. succinogenes, $R$. albus, $R$. flavefaciens, and B. fibrisolvens (Krause et al., 2003). However, anaerobic fungi (McAllister et al., 1994; Krause et al., 2003) and protozoa (Devillard et al., 2003) have also been shown to possess the enzymatic pool to carry over fiber digestion.

A relevant connection exists between fiber digestion and methane production in the rumen. Fibrolytic bacteria seem to possess a role in methane production as they are involved in $\mathrm{H}_{2}$ production (Ruminococcus, Eubacterium) or consumption (members of the Bacteroidetes; Tapio et al., 2017). Moreover, according to Moss et al. (2000), the production of acetic acid in the rumen is associated with increased $\mathrm{H}_{2}$ production, thus leading to a greater availability of substrates needed for methane production. Indeed, the microbiome of high-methane producing animals is different from that of low-methane-producing animals (Danielsson et al., 2017; Tapio et al., 2017).

Tannins have been shown to reduce the degradation of fiber (Barry and Mc Nabb, 1999; Hervás et al., 2003); however, the mechanism of action is not fully understood. Fiber degradation requires at least the following steps: the transport of the microorganisms to plant substrate, the nonspecific adhesion of microorganisms to plant cell wall, the specific adhesion with a substrate, and the proliferation of microorganisms on the substrate (Krause et al., 2003). It has been proposed that tannins might prevent the attachment of microorganisms to plant cell walls (McAllister et al., 1994), inhibit microbial degrading enzymes, or alter the functionality of ruminal microorganisms (Jones et al., 1994).

Table 2 reviews the effects of dietary $\mathrm{PP}$ on the production of VFA as final products of dietary carbohydrate fermentation. In Table 2, only studies investigating the effect of dietary PP on VFA production coupled with analysis of the rumen microbiota were considered. Nine out of 15 studies are in vitro experiments, whereas the remaining 6 studies are in vivo experiments, largely based on small ruminants (sheep) as the animal model. Ten studies are based on the use of CT or HT extracts as the source of PP, whereas the remaining papers are related to the use of mix of different kind of oligomeric PP, flavonoids, or resveratrol (Table 2). The effect of CT in the in vitro studies on VFA production is quite consistent: a reduction of total 
VFA production associated with a reduction of acetate, and in some cases, with an increase of propionate production. Unfortunately, data from in vivo experiments where carbohydrates fermentation has been evaluated along with rumen microbiota composition are quite scarce. In the case of $\mathrm{CT}$, the only experiment included in the table showed a positive effect of $\mathrm{CT}$ on total VFA and propionate and a negative effect on acetate. Consistently, the relative abundance of fibrolytic bacteria in the rumen digesta decreased. Condensed tannins have been associated with a direct inhibitory effect on rumen microbial activity. In a recent study aimed to compare different types of $\mathrm{CT}$ and HT on rumen metabolism in fistulated sheep, CT significantly reduced rumen VFA concentration, mostly acetate (Costa et al., 2018). In the same study, the authors reported differential responses of rumen bacteria to CT and HT. In particular, some gram-positive specialized fibrolytic bacteria such as $F$. succinogenes, $R$. albus, $R$. flavefaciens, and $B$. proteoclasticus were more susceptible to CT than gram-negative rumen bacteria such as Selenomonas ruminantium and $P$. bryantii. These results suggested that gram-negative bacteria are less affected by $\mathrm{CT}$ than gram-positive bacteria. Interestingly, a differential effect of $\mathrm{HT}$ and $\mathrm{CT}$ on fibrolytic bacteria was suggested also by Buccioni et al. (2015a), who compared diets supplemented with chestnut or quebracho tannins. When dairy sheep were fed diet supplemented with chestnut tannins, the amount of VFA and acetate increased, along with the relative abundance of $B$. fibrisolvens. Conversely, the diet supplemented with quebracho tannins resulted in a decrease of total VFA and acetate production. It is worth mentioning that in the case of nontannic PP, the effect on total VFA and acetic acid was null or, occasionally, negative both in in vitro and in vivo experiments. Unfortunately, the effect on rumen microbiota composition was mainly focused on methanogen microbes.

It is now ascertained that tannins reduce methane emission (Hook et al., 2010), and so far, direct inhibitory effects of tannins upon methanogens were shown. Jayanegara et al. (2012), after a meta-analysis including data from a total of 30 experiments consisting of 171 treatments (both in vitro and in vivo), clearly stated that with any approach, methane declined when dietary tannins increased. Moreover, in vitro experiments predicted the in vivo response quite accurately (Jayanegara et al., 2012). However, the number of experiments where the effect of dietary PP (both tannic and nontannic) on methane production was measured along with the composition of rumen microbiota is still scarce. In Table 3, 14 studies reporting this kind of information were selected. Eight out of 14 are in vitro experiments, whereas the remaining 6 are in vivo experiments, 3 on sheep, 2 on dairy cattle, and 1 on beef cattle. In vitro experiments usually provided the largest range of variation in terms of methane production mitigation (minimum 6.3\%, maximum 65\%), whereas in vivo experiments ranged between 10 to $30 \%$, with more frequent values around 15 to $20 \%$.

Besides the direct effect of tannins on methanogens (reported for almost all the studies included in the table), the overall effect of tannins on the consortium of ruminal microorganisms must also be evaluated. Considering that archaea are in association with protozoa, the reduced protozoa population on the presence of tannins could partly contribute to explain results about decreased methane production. More than half of the studies included in the Table 3 reported an overall depressive effect of dietary PP on both total methanogen and protozoa populations. This is not surprising, since, as previously reported in the present review, a strong association exists between protozoa populations and methanogens. Moreover, a shift in protozoa populations from type-A ciliate communities to B-type communities was associated with a decrease in methane production (Kittelmann and Janssen, 2011).

Tavendale et al. (2005) tested the in vitro effect of tannins from L. pedunculatus on M. ruminantium strains YLM-1 and DSM1093, and found that the oligomeric fraction of tannins did not have effects on microbial activity, whereas the polymeric fraction did. Ross et al. (2013) reported that the supplementation of tannins to dairy cattle reduced methane emission and altered the rumen microbiome of animals supplemented or not with tannins separately clustered.

Also, flavonoids have been suggested to indirectly reduce ruminal methanogenesis, acting as $\mathrm{H}_{2}$ sinks (Becker et al., 2013). Conversely, other studies have reported a direct inhibitory effect of flavonoids on methanogens (Seradj et al., 2014).

Some authors suggest that the concomitant reduction of fiber digestion could contribute to the lower methane production in the rumen of tannin-fed animals (Patra et al., 2012). However, according to Goel and Makkar (2012), this explanation could be applied to CT that are usually associated with a reduction of fiber digestion. As far as HT, evidence in the literature suggests a direct effect on methane emission, by acting through inhibition of the growth and activity of methanogens and hydrogen-producing microbes (Goel and Makkar, 2012). Moreover, early studies on the rumen degradation of HT reported that specific rumen bacteria, such as Eubacterium oxidoreducens, can degrade metabolites of HT (gallate, pyrogallol, phloroglucinol) to acetate and butyrate by using $\mathrm{H}_{2}$ and formate, suggesting a po- 
tential role of this pathway in the reduction of methane production (Krumholz and Bryant, 1986).

\section{CONCLUSIONS}

With the advances in technologies (from traditional techniques to the use of NGS platforms) for the characterization of microbial communities, data available in the literature about rumen microbiota composition are quickly growing. Cultivation-independent methods (e.g., high-throughput sequencing of the $16 \mathrm{~S}$ rRNA gene) seem to be more powerful than previous techniques (i.e., based on isolation and cultivation) for the study of microbial ecosystems, as only few microorganisms are cultivable. The approach of "omics," such as metagenomics and metatranscriptomics, led to new opportunities for the investigation of rumen microbiota diversity and metabolism. Furthermore, metabolomics and metaproteomics could help to increase understanding of the interaction between the microbiome and their metabolites, so to unravel the possible interactions between microorganisms and specific dietary ingredients, such as PP.

Although some contrasting results are present in the literature, overall, dietary $\mathrm{PP}$ are able to modulate the rumen microbiota composition by negatively affecting some species of fibrolytic bacteria and ciliate protozoa. Differences have been reported between CT and HT: the former usually inhibit the $\mathrm{BH}$ process, whereas the latter modulate $\mathrm{BH}$. A modulating effect on $\mathrm{BH}$ has also been reported for other types of PP, such as PP from olive pomace (aglycone derivatives of native secoiridoid glucosides, namely oleuropein, dimethyl oleuropein, and ligstroside). Thanks to the modern molecular techniques of analysis, the tannin-depending shifts in the microbial communities have revealed a role in $\mathrm{BH}$ of dietary lipids for some uncultured bacterial strains. Although differences have been reported according to the nature and the amounts of PP in the diet, the supplementation of PP seems to be effective in preserving PUFA, RA, and VA from a complete $\mathrm{BH}$, thus enriching meat and milk in health-promoting fatty acids, at the expense of SFA. The effects of PP on cellulolytic bacteria, particularly on gram-positive, and protozoa probably are also associated with the reduction of both fiber degradability and, indirectly, with methane emission. However, some authors have suggested that a direct interaction between some specific PP (such as HT) and methanogen microbes is also possible.

\section{ACKNOWLEDGMENTS}

This research was financed by the University of Pisa.

\section{REFERENCES}

Abbeddou, S., B. Rischkowsky, E. K. Richter, H. D. Hess, and M. Kreuzer. 2011. Modification of milk fatty acid composition by feeding forages and agro-industrial byproducts from dry areas to Awassi sheep. J. Dairy Sci. 94:4657-4668. https://doi.org/10 $.3168 /$ jds.2011-4154.

Aiman-Zakaria, A., G. Yong-Meng, M. Ali-Rajion, S. Jafari, M. Faseleh-Jahromi, P. Shokriyazdan, and M. Ebrahimi. 2017. The influence of plant polyphenols from oil palm (Elaeis guineensis Jacq.) leaf extract on fermentation characteristics, biohydrogenation of C18 PUFA, and microbial populations in rumen of goats: In vitro study. Acta Agric. Scand. A Anim. Sci. 67:76-84.

Andrés, A., R. Bodas, M. L. Tejido, F. J. Giráldez, C. Valdés, and S. López. 2016. Effects of the inclusion of flaxseed and quercitin in the diet of fattening lambs on ruminal microbiota, in vitro, fermentation and biohydrogenation of fatty acids. J. Agric. Sci. 154:542-552. https://doi.org/10.1017/S0021859615001094.

Bainbridge, M. L., L. M. Cersosimo, A. D. G. Wright, and J. Kraft. 2016. Rumen bacterial communities shift across a lactation in Holstein, Jersey and Holstein 9 Jersey dairy cows and correlate to rumen function, bacterial fatty acid composition and production parameters. FEMS Microbial Ecol. 92:fiw059.

Baker, G. C., J. J. Smith, and D. A. Cowan. 2003. Review and reanalysis of domain-specific 16S primers. J. Microbiol. Methods 55:541-555. https://doi.org/10.1016/j.mimet.2003.08.009.

Barry, T. N., and W. C. McNabb. 1999. The implications of condensed tannins on the nutritive value of temperate forages fed to ruminants. Br. J. Nutr. 81:263-272.

Bauchart, D., F. Lagay-Carmier, M. Doreau, and B. Gaillard. 1990. Lipid metabolism of liquid-associated and solid-adherent bacteria in rumen contents of dairy cows offered lipid-supplemented diets. Br. J. Nutr. 63:563-578.

Becker, P. M., P. G. van Wikselaar, M. C. R. Franssen, R. C. H. de Vos, R. D. Hall, and J. Beekwilder. 2013. Evidence for a hydrogensink mechanism of $(+)$ catechin mediated emission reduction of the ruminant greenhouse gas methane. Metabolomics 10:179-189. https://doi.org/10.1007/s11306-013-0554-5.

Belanche, A., M. Doreau, J. E. Edwards, J. M. Moorby, E. Pinloche, and C. J. Newbold. 2012. Shifts in the rumen microbiota due to the type of carbohydrate and level of protein ingested by dairy cattle are associated with changes in rumen fermentation. J. Nutr. 142:1684-1692. https://doi.org/10.3945/jn.112.159574.

Béra-Maillet, C., P. Mosoni, A. Kwasiborski, F. Suau, Y. Ribot, and E. Forano. 2009. Development of a RT-qPCR method for the quantification of Fibrobacter succinogenes S85 glycoside hydrolase transcripts in the rumen content of gnotobiotic and conventional sheep. J. Microbiol. Methods 77:8-16. https://doi.org/10.1016/j .mimet.2008.11.009.

Bertolini, V., I. Gandolfi, R. Ambrosini, G. Bestetti, E. Innocente, G. Rampazzo, and A. Franzetti. 2013. Temporal variability and effect of environmental variables on airborne bacterial communities in an urban area of Northern Italy. Appl. Microbiol. Biotechnol. 97:6561-6570. https://doi.org/10.1007/s00253-012-4450-0.

Bessa, R. J. B., M. R. G. Maia, E. Jeronimo, A. T. Belo, A. R. J. Cabrita, R. J. Dewhurst, and A. J. M. Fonseca. 2009. Using microbial fatty acids to improve understanding of the contribution of solid associated bacteria to microbial mass in the rumen. Anim. Feed Sci. Technol. 150:197-206. https://doi.org/10.1016/j .anifeedsci.2008.09.005.

Bhat, T. K., B. Singh, and O. P. Sharma. 1998. Microbial degradation of tannins-A current perspective. Biodegradation 9:343-357.

Bravo, L. 1998. Polyphenols: Chemistry, dietary sources, metabolism, and nutritional significance. Nutr. Rev. 56:317-333.

Brulc, J. M., D. A. Antonopoulos, M. E. Berg Miller, M. K. Wilson, A. C. Yannarell, E. A. Dinsdale, R. E. Edwards, E. D. Frank, J. B. Emerson, P. Wacklin, P. M. Coutinho, B. Henrissat, K. E. Nelson, and B. A. White. 2009. Gene-centric metagenomics of the fiberadherent bovine rumen microbiome reveals forage specific glycoside hydrolases. Proc. Natl. Acad. Sci. USA 106:1948-1953. https: //doi.org/10.1073/pnas.0806191105. 
Buccioni, A., S. Minieri, S. Rapaccini, M. Antongiovanni, and M. Mele. 2011. Effect of chestnut and quebracho tannins on fatty acid profile in rumen liquid- and solid-associated bacteria: an in vitro study. Animal 5:1521-1530. https://doi.org/10.1017/ S1751731111000759.

Buccioni, A., G. Pallara, R. Pastorelli, L. Bellini, A. Cappucci, F. Mannelli, S. Minieri, V. Roscini, S. Rapaccini, M. Mele, L. Giovannetti, C. Viti, and M. Pauselli. 2017. Effect of dietary chestnut or quebracho tannin supplementation on microbial community and fatty acid profile in the rumen of dairy ewes. Biomed Res. Int. 2017:4969076. https://doi.org/10.1155/2017/4969076.

Buccioni, A., M. Pauselli, C. Viti, S. Minieri, G. Pallara, V. Roscini, S. Rapaccini, M. Trabalza Marinucci, P. Lupi, G. Conte, and M. Mele. 2015a. Milk fatty acid composition, rumen microbial population, and animal performances in response to diets rich in linoleic acid supplemented with chestnut or quebracho tannins in dairy ewes. J. Dairy Sci. 98:1145-1156. https://doi.org/10.3168/jds.2014 -8651 .

Buccioni, A., A. Serra, S. Minieri, F. Mannelli, A. Cappucci, D. Benvenuti, S. Rapaccini, G. Conte, and M. Mele. 2015b. Milk production, composition, and milk fatty acid profile from grazing sheep fed diets supplemented with chestnut tannin extract and extruded linseed. Small Rumin. Res. 130:200-207. https://doi.org/10.1016/ j.smallrumres.2015.07.021.

Cabiddu, A., L. Salis, J. K. S. Tweed, G. Molle, M. Decandia, and M. R. F. Lee. 2010. The influence of plant polyphenols on lipolysis and biohydrogenation in dried forages at different phenological stages: in vitro, study. J. Sci. Food Agric. 90:829-835. https://doi .org/10.1002/jsfa.3892.

Caldwell, D. R., and M. P. Bryant. 1966. Medium without rumen fluid for non selective enumeration and isolation of rumen bacteria. Appl. Microbiol. 14:794-801.

Cappucci, A., S. P. Alves, R. J. B. Bessa, A. Buccioni, F. Mannelli, M. Pauselli, C. Viti, R. Pastorelli, V. Roscini, A. Serra, G. Conte, and M. Mele. 2018. Effect of increasing amounts of olive crude phenolic concentrate in the diet of dairy ewes on rumen liquor and milk fatty acid composition. J. Dairy Sci. 101:4992-5005.

Carreño, D., G. Hervás, P. G. Toral, A. Belenguer, and P. Frutos. 2015. Ability of different types and doses of tannin extracts to modulate in vitro ruminal biohydrogenation in sheep. Anim. Feed Sci. Technol. 202:42-51. https://doi.org/10.1016/j.anifeedsci.2015 .02 .003 .

Chakravorty, S., D. Helb, M. Burday, N. Connell, and D. Alland. 2007. A detailed analysis of $16 \mathrm{~S}$ ribosomal RNA gene segments for the diagnosis of pathogenic bacteria. J. Microbiol. Methods 69:330 339. https://doi.org/10.1016/j.mimet.2007.02.005.

Choudhury, P. K., A. Z. M. Salem, R. Singh, and A. K. Puniya. 2015. Rumen microbiology: An overview. Pages 3-16 in Rumen Microbiology: From Evolution to Revolution. A. K. Puniya, R. Singh, and D. N. Kamra, ed. Springer, India. https://doi.org/10.1007/978-81 -322-2401-3_1.

Costa, M., S. P. Alves, A. Cappucci, S. R. Cook, A. Duarte, R. M. Caldeira, T. A. McAllister, and R. J. B. Bessa. 2018. Effects of condensed and hydrolyzable tannins on rumen metabolism with emphasis on the biohydrogenation of unsaturated fatty acids. J. Agric. Food Chem. 66:3367-3377. https://doi.org/10.1021/acs.jafc $.7 \mathrm{~b} 04770$.

Czerkawski, J. W. 1986. An Introduction to Rumen Studies. Pergamon Press, Oxford, UK.

Daghio, M., V. Tatangelo, A. Franzetti, I. Gandolfi, M. Papacchini, A. Careghini, E. Sezenna, S. Saponaro, and G. Bestetti. 2015. Hydrocarbon degrading microbial communities in bench scale aerobic biobarriers for gasoline contaminated groundwater treatment. Chemosphere 130:34-39. https://doi.org/10.1016/j.chemosphere 2015.02.022

Danielsson, R., J. Dicksved, L. Sun, H. Gonda, B. Müller, A. Schnürer, and J. Bertilsson. 2017. Methane production in dairy cows correlates with rumen methanogenic and bacterial community structure. Front. Microbiol. 8:226. https://doi.org/10.3389/fmicb.2017 .00226 .
De Nardi, R., G. Marchesini, S. Li, K. J. C. Plaizer, M. Gianesella, R. Ricci, I. Andrighetto, and S. Segato. 2016. Metagenomic analysis of rumen microbial population in dairy heifers fed a high grain diet supplemented with dicarboxylic acids or polyphenols. BMC Vet. Res. 12:29. https://doi.org/10.1186/s12917-016-0653-4.

Dehority, B. A. 1966. Characterization of several bovine rumen bacteria isolated with a xylan medium. J. Bacteriol. 91:1724-1729.

Deng, W., D. Xi, H. Mao, and M. Wanapat. 2008. The use of molecular techniques based on ribosomal RNA and DNA for rumen microbial ecosystem studies: A review. Mol. Biol. Rep. 35:265-274. https://doi.org/10.1007/s11033-007-9079-1.

Devillard, E., C. Bera-Millet, H. J. Flint, K. P. Scott, C. J. Newbold, R. J. Wallace, J. P. Jouany, and E. Forano. 2003. Characterization of XYN10B, a modular xylanase from the ruminal protozoan Polyplastron multivvesiculatum, with a family 22 carbohydrate-binding module that binds to cellulose. Biochem. J. 373:495-503. https:// doi.org/10.1042/BJ20021784.

Dieho, K., B. van den Bogert, G. Handerson, A. Bannink, J. RamiroGarcia, H. Smidt, and J. Dijkstra. 2017. Changes in rumen microbiota composition and in situ degradation kinetics during the dry period and early lactation as affected by rate of increase of concentrate allowance. J. Dairy Sci. 100:2695-2710. https://doi .org/10.3168/jds.2016-11982.

Dschaak, C. M., C. M. Williams, M. S. Holt, J. S. Eun, A. J. Young, and B. R. Min. 2011. Effects of supplementing condensed tannin extract on intake, digestion, ruminal fermentation, and milk production of lactating dairy cows. J. Dairy Sci. 94:2508-2519. https: //doi.org/10.3168/jds.2010-3818.

Edwards, J. E., R. J. Forster, T. M. Callaghan, V. Dollhofer, S. S. Dagar, Y. Cheng, J. Chang, S. Kittelmann, K. Fliegerova, A. K. Puniya, J. K. Henske, S. P. Gilmore, M. A. O'Malley, G. W. Griffith, and H. Smidt. 2017. PCR and omics based techniques to study the diversity, ecology and biology of anaerobic fungi: Insights, challenges and opportunities. Front. Microbiol. 8:1657. https://doi.org/10.3389/fmicb.2017.01657.

Elekwachi, C. O.. Z. Wang, X. Wu, A. Rabee, and R. J. Forster. 2017. Total rRNA-seq analysis gives insight into bacterial, fungal, protozoal and archaeal communities in the rumen using an optimized RNA isolation method. Front. Microbiol. 8:1814. https://doi.org/ 10.3389/fmicb.2017.01814.

Ellison, M. J., G. C. Conant, W. R. Lamberson, R. R. Cockrum, K. J. Austin, and D. C. Rule. 2017. Diet and feed efficiency status affect rumen microbial profiles of sheep. Small Rumin. Res. 156:12-19. https://doi.org/10.1016/j.smallrumres.2017.08.009.

Enjalbert, F., S. Combes, A. Zened, and A. Meynadier. 2017. Rumen microbiota and dietary fat: a mutual shaping. J. Appl. Microbiol. 123:782-797.

Fernando, S. C., H. T. Purvis, F. Z. Najar, L. O. Sukharnikov, C. R. Krehbiel, T. G. Nagaraja, B. A. Roe, and U. DeSilva. 2010. Rumen microbial population dynamics during adaptation to a highgrain diet. Appl. Environ. Microbiol. 76:7482-7490. https://doi .org/10.1128/AEM.00388-10.

Firkins, J. L., and Z. Yu. 2015. Ruminant Nutrition Symposium: How to use data on the rumen microbiome to improve our understanding of ruminant nutrition. J. Anim. Sci. 93:1450-1470. https://doi .org/10.2527/jas.2014-8754

Fisher, M. M., and E. W. Triplett. 1999. Automated approach for ribosomal intergenic spacer analysis of microbial diversity and its application to freshwater bacterial communities. Appl. Environ. Microbiol. 65:4630-4636.

Flachowsky, G., U. Meyer, and K. H. Südekum. 2017. Land use for edible protein of animal origin-A review. Animals (Basel) 7:25. https://doi.org/10.3390/ani7030025.

Fouts, D. E., S. Szpakowski, J. Purushe, M. Torralba, R. C. Waterman, M. D. Macneil, L. J. Alexander, and K. E. Nelson. 2012. Next generation sequencing to define prokaryotic and fungal diversity in the bovine rumen. PLoS One 7:e48289. https://doi.org/10 .1371/journal.pone.0048289.

Fraisse, D., A. Carnat, D. Viala, P. Pradel, J.-M. Besle, J.-B. Coulon, C. Felgines, and J.-L. Lamaison. 2007. Polyphenolic composition of a permanent pasture: Variations related to the period of har- 
vesting. Sci. Food Agric. 13:2427-2435. https://doi.org/10.1002/ jsfa.2918.

Franzosa, E. A., T. Hsu, A. Sirota-Madi, A. Shafquat, G. Abu-Ali, X. C. Morgan, and C. Huttenhower. 2015. Sequencing and beyond: Integrating molecular "omics" for microbial community profiling. Nat. Rev. Microbiol. 13:360-372. https://doi.org/10.1038/ nrmicro3451.

Frutos, P., G. Hervas, F. J. Giraldez, and A. R. Mantecon. 2004. Review. Tannins and ruminant nutrition. Span. J. Agric. Res. $2: 19-202$

Gilbert, J. A., and C. L. Dupont. 2011. Microbial metagenomics: Beyond the genome. Ann. Rev. Mar. Sci. 3:347-371. https://doi.org/ 10.1146/annurev-marine-120709-142811.

Goel, G., and H. P. S. Makkar. 2012. Methane mitigation from ruminants using tannins and saponins. Trop. Anim. Health Prod. 44:729-739. https://doi.org/10.1007/s11250-011-9966-2.

Goodwin, S., J. D. McPherson, and W. R. McCombie. 2016. Coming of age: Ten years of next-generation sequencing technologies. Nat. Rev. Genet. 17:333-351. https://doi.org/10.1038/nrg.2016.49.

Granja-Salcedo, Y. T., R. A. Ramirez-Uscategui, E. G. Machado, J. D. Messana, L. T. Kishi, A. V. L. Dias, and T. T. Berchielli. 2017. Studies on bacterial community composition are affected by the time and storage method of the rumen content. PLoS One 12:e0176701. https://doi.org/10.1371/journal.pone.0176701.

Grilli, D. J., K. Fliegerovà, J. Kopecný, S. Paez Lama, V. Egea, N. Sohafefer, C. Pereyra, M. S. Ruiz, M. A. Sosa, G. N. Arenas, and J. Mràzek. 2016. Analysis of the rumen bacterial diversity of goats during shifts from forage to concentrate diet. Anaerobe 42:17-26. https://doi.org/10.1016/j.anaerobe.2016.07.002.

Henderson, G., F. Cox, S. Ganesh, A. Jonker, W. YoungGlobal Rumen Census Collaborators, and P. H. Janssen. 2015. Rumen microbial community composition varies with diet and host, but a core microbiome is found across a wide geographical range. Sci. Rep. 5:14567. 10.1038/srep14567.

Hervás, G., P. Frutos, F. J. Giraldes, A. R. Mantecon, and M. C. Álvarez del Pino. 2003. Effect of different doses of quebracho tannins extract on rumen fermentation in ewes. Anim. Feed Sci. Technol. 109:65-78.

Hook, S. E., A.-D. G. Wright, and B. W. McBride. 2010. Methanogens: Methane producers of the rumen and mitigation strategies. Archaea 2010:945785. https://doi.org/10.1155/2010/945785.

Hungate, R. E. 1966. The Rumen and Its Microbes. Academic Press, New York, NY.

Huws, S. A., E. J. Kim, M. R. F. Lee, M. B. Scott, J. K. S. Tweed, E. Pinloche, R. J. Wallace, and N. D. Scollan. 2011. As yet uncultured bacteria phylogenerically classified as Prevotella, Lachnospiraceae incertae sedis and unclassified Bacteroidales, Clostridiales and Ruminococcaceae may play a predominant role in ruminal biohydrogenation. Environ. Microbiol. 13:1500-1512. https://doi.org/ 10.1111/j.1462-2920.2011.02452.x.

Ishlak, A., M. Günal, and A. A. AbuGhazaleh. 2015. The effects of cinnamaldehyde, monensin and quebracho condensed tannin on rumen fermentation, biohydrogenation and bacteria in continuous culture system. Anim. Feed Sci. Technol. 207:31-40. https://doi .org/10.1016/j.anifeedsci.2015.05.023.

Jafari, S., G. Y. Meng, M. A. Rajion, M. F. Jahromi, and M. Ebrahimi. 2016. Manipulation of rumen microbial fermentation by poliphenol rich solvent fractions from papaya leaf to reduce green-house gas methane and biohydrogenation of C18 PUFA. J. Agric. Food Chem. 64:4522-4530. https://doi.org/10.1021/acs.jafc.6b00846.

Jami, E., A. Israel, A. Kotser, and I. Mizrahi. 2013. Exploring the bovine rumen bacterial community from birth to adulthood. ISME J. 7:1069-1079. https://doi.org/10.1038/ismej.2013.2.

Jami, E., and I. Mizrahi. 2012. Composition and similarity of bovine rumen microbiota across individual animals. PLoS One 7. https:/ /doi.org/10.1371/journal.pone.0033306.

Jayanegara, A., G. Goel, H. P. S. Makkar, and K. Becker. 2015. Divergence between purified hydrolysable and condensed tannin effects on methane emission, rumen fermentation and microbial population in vitro. Anim. Feed Sci. Technol. 209:60-68.
Jayanegara, A., F. Leiber, and M. Kreuzer. 2012. Meta-analysis of the relationship between dietary tannin level and methane formation in ruminants from in vivo and in vitro experiments. J. Anim. Physiol. Anim. Nutr. (Berl.) 96:365-375.

Jerónimo, E., S. P. Alves, M. T. P. Dentinho, S. V. Martins, J. A. M. Prates, V. Vasta, J. Santos-Silva, and R. J. B. Bessa. 2010. Effect of grape seed extract, Cistus ladanifer L., and vegetable oil supplementation on fatty acid composition of abomasal digesta and intramuscular fat of lambs. J. Agric. Food Chem. 58:10710-10721. https://doi.org/10.1021/jf1021626.

Jewell, K. A., C. A. McCormick, C. L. Odt, P. J. Weimer, and G. Suen. 2015. Ruminal bacterial community composition in dairy cows is dynamic over the course of two lactations and correlates with feed efficiency. Appl. Environ. Microbiol. 81:4697-4710. https://doi.org/10.1128/AEM.00720-15.

Jones, G. A., T. A. McAllister, A. D. Muir, and K.-J. Cheng. 1994. Effects of sainfoin (Onobrichys viciifolia Scop.) condensed tannins on growth and proteolysis by four strains of ruminal bacteria. Appl. Environ. Microbiol. 60:1374-1378.

Ju, F., and T. Zhang. 2015. 16S rRNA gene high-throughput sequencing data mining of microbial diversity and interactions. Appl. Microbiol. Biotechnol. 99:4119-4129. https://doi.org/10.1007/s00253 $-015-6536-\mathrm{y}$.

Kepler, C. R., and S. B. Tove. 1967. Biohydrogenation of unsaturated fatty acids III. Purification and properties of a linoleate $\Delta^{12}$-cis, $\Delta^{11}$-trans-isomerase from Butyrivibrio fibrisolvens. J. Biol. Chem. 242:5686-5692.

Khiaosa-Ard, R., S. F. Bryner, M. E. L. Scheeder, H.-R. Wettstein, F. Leiber, M. Kreuzer, and C. R. Soliva. 2009. Evidence for the inhibition of the terminal step of ruminal $\alpha$-linolenic acid biohydrogenation by condensed tannins. J. Dairy Sci. 92:177-188. https: //doi.org/10.3168/jds.2008-1117.

Kim, M., T. Park, and Z. Yu. 2017. Metagenomic investigation of gastrointestinal microbiome in cattle. Asian-australas. J. Anim. Sci. 30:1515-1528. https://doi.org/10.5713/ajas.17.0544.

Kittelmann, S., and P. H. Janssen. 2011. Characterization of rumen ciliate community composition in domestic sheep, deer, and cattle, feeding on varying diets, by means of PCR-DGGE and clone libraries. FEMS Microbiol. Ecol. 75:468-481. https://doi.org/10 .1111/j.1574-6941.2010.01022.x.

Kittelmann, S., H. Seedorf, W. A. Walters, J. C. Clemente, R. Knight, J. I. Gordon, and P. H. Janssen. 2013. Simultaneous amplicon sequencing to explore co-occurrence patterns of bacterial, archaeal and eukaryotic microorganisms in rumen microbial communities. PLoS One 8:e47879. https://doi.org/10.1371/journal.pone .0047879 .

Koike, S., and Y. Kobayashi. 2001. Development and use of competitive PCR assays for the rumen cellulolytic bacteria: Fibrobacter succinogenes, Ruminococcus albus and Ruminococcus flavefaciens. FEMS Microbiol. Lett. 204:361-366.

Kong, Y., R. Teather, and R. Foster. 2010. Composition, spatial distribution, and diversity of the bacterial communities in the rumen of cows fed different forages. FEMS Microbiol. Ecol. 74:612-622. https://doi.org/10.1111/j.1574-6941.2010.00977.x.

Krause, D. O., S. E. Denman, R. I. Mackie, M. Morrison, A. L. Rae, G. T. Attwood, and C. S. McSweeney. 2003. Opportunities to improve fibre degradation in the rumen: Microbiology, ecology and genomics. FEMS Microbiol. Rev. 27:663-693. https://doi.org/10.1016/ S0168-6445(03)00072-X.

Krumholz, L. R., and M. P. Bryant. 1986. Eubacterium oxidoreducens sp. nov. requiring $\mathrm{H} 2$ or formate to degrade gallate, pyrogallol, phloroglucinol and quercetin. Arch. Microbiol. 144:8-14.

Kumar, S., P. K. Choudhury, M. D. Carro, G. W. Griffith, S. S. Dagar, M. Puniya, S. Calabro, S. R. Ravella, T. Dhewa, R. C. Upadhyay, S. K. Sirohi, S. S. Kundu, M. Wanapat, and A. K. Puniya. 2014 New aspects and strategies for methane mitigation from ruminants. Appl. Microbiol. Biotechnol. 98:31-44.

Kumar, S., N. Indugu, B. Vecchiarelli, and D. W. Pitta. 2015. Associative patterns among anaerobic fungi, methanogenic archaea, and bacterial communities in response to changes in diet and age in the 
rumen of dairy cows. Front. Microbiol. 6:781. https://doi.org/10 .3389 /fmicb.2015.00781.

Landau, S., G. Molle, N. Fois, S. Friedman, D. Barkai, M. Decandia, A. Cabiddu, L. Dvash, and M. Sitzia. 2005. Safflower (Carthamus tinctorius L.) as a novel pasture species for daily sheep in the Mediterranean conditions of Sardinia and Israel. Small Rumin. Res. 59:239-249.

Landau, S., A. Perevolotsky, D. Bonfil, and N. Silanikove. 2000. Utilization of low quality resources by small ruminants in Mediterranean agro-pastoral systems: the case of browse and aftermath cereal stubble. Livest. Prod. Sci. 64:39-49.

Lederberg, J., and A. T. McCray. 2001. 'Ome sweet 'omics: a genealogical treasury of words. Scientist 15:8.

Lee, M. R. F., J. K. S. Tweed, A. Cooksona, and M. L. Sullivan. 2010. Immunogold labelling to localize polyphenol oxidase (PPO) during wilting of red clover leaf tissue and the effect of removing cellular matrices on PPO protection of glycerol-based lipid in the rumen. J. Sci. Food Agric. 90:503-510.

Lees, G. L. 1992. Condensed tannins in some forage legumes: their role in the prevention of ruminant pasture bloat. Basic Life Sci. 59:915-934.

Li, F., G. Henderson, X. Sun, F. Cox, P. H. Janssen, and L. L. Guan. 2016. Taxonomic assessment of rumen microbiota using total RNA and targeted amplicon sequencing approaches. Front. Microbiol. 7:987. https://doi.org/10.3389/fmicb.2016.00987.

Li, F., A. L. A. Neves, B. Ghoshal, and L. L. Guan. 2018. Mining metagenomic and metatranscriptomic data for clues about microbial metabolic functions in ruminants. J. Dairy Sci. https://doi .org/10.3168/jds.2017-13356 (Article in press).

Liggenstoffer, A. S., N. H. Youssef, M. B. Couger, and M. S. Elshahed. 2010. Phylogenetic diversity and community structure of anaerobic fungi (phylum Neocallimastigomycota) in ruminant and non-ruminant herbivores. ISME J. 4:1225-1235. https://doi.org/ 10.1038/ismej.2010.49.

Liu, W. T., T. L. Marsh, H. Cheng, and L. J. Forney. 1997. Characterization of microbial diversity by determining terminal restriction fragment length polymorphisms of genes encoding 16S rRNA. Appl. Environ. Microbiol. 63:4516-4522.

Liu, H., V. Vaddella, and D. Zhou. 2011. Effects of chestnut tannins and coconut oil on growth performance, methane emission, ruminal fermentation, and microbial populations in sheep. J. Dairy Sci. 94:6069-6077. https://doi.org/10.3168/jds.2011-4508.

Lourenço, M., E. Ramos-Morales, and R. J. Wallace. 2010. The role of microbes in rumen lipolysis and biohydrogenation and their manipulation. Animal 4:1008-1023. https://doi.org/10.1017/ S175173111000042X

Ma, T., D. D. Chen, Y. Tu, N. F. Zhang, B. W. Si, K. D. Deng, and Q. Y. Diao. 2015. Effect of dietary supplementation with resveratrol on nutrient digestibility, methanogenesis and ruminal microbial flora in sheep. J. Anim. Physiol. Anim. Nutr. (Berl.) 99:676-683.

Ma, T., D. D. Chen, Y. Tu, N. F. Zhang, B. W. Si, and Q.-Y. Diao. 2017. Dietary supplementation with mulberry leaf flavonoids inhibits methanogenesis in sheep. Anim. Sci. J. 88:72-78.

Makkar, H. P. S. 2003. Effects and fate of tannins in ruminant animals, adaptation to tannins, and strategies to overcome detrimental effects of feeding tannin-rich feeds. Small Rumin. Res. 49:241-256.

Makkar, H. P. S., and P. Ankers. 2014. Towards sustainable animal diets. A survey-based study. Anim. Feed Sci. Technol. 198:309-322. https://doi.org/10.1016/j.anifeedsci.2014.09.018.

Mannelli, F., A. Cappucci, F. Pini, R. Pastorelli, F. Decorosi, L. Giovannetti, M. Mele, S. Minieri, G. Conte, M. Pauselli, S. Rapaccini, C. Viti, and A. Buccioni. 2018. Effect of different types of olive oil pomace dietary supplementation on the rumen microbial community profile in Comisana ewes. Sci. Rep. 8:8455. https://doi .org/10.1038/s41598-018-26713-w.

McAllister, T. A., H. D. Bae, G. A. Jones, K. J. Cheng, and A. Miur. 1994. Effect of condensed tannins from birdfoot trefoil on the endoglucanase activity and the digestion of cellulose filter paper by ruminal fungi. Can. J. Microbiol. 40:298-305.
McSweeney, C. S., S. E. Denman, A.-D.-G. Wright, and Z. Yu. 2007. Application of recent DNA/RNA-based techniques in rumen ecology. Asian-Aust. J. Anim. Sci. 20:283-294.

Min, B. R., T. N. Barry, G. T. Attwood, and W. C. McNabb. 2003 The effect of condensed tannins on the nutrition and health of ruminants fed fresh temperate forages: A review. Anim. Feed Sci Technol. 106:3-19.

Mitra, S., K. Förster-Fromme, A. Damms-Machado, T. Scheurenbrand, S. Biskup, D. H. Huson, and S. C. Bischoff. 2013. Analysis of the intestinal microbiota using SOLiD 16S rRNA gene sequencing and SOLiD shotgun sequencing. BMC Genomics 14:S16. https: //doi.org/10.1186/1471-2164-14-S5-S16.

Moate, P. J., S. R. Williams, V. A. Torok, M. C. Hannah, B. E. Ribaux, M. H. Tavendale, R. J. Eckard, J. L. Jacobs, M. J. Auldist, and W. Wales. 2014. Grape marc reduces methane emissions when fed to dairy cows. J. Dairy Sci. 97:5073-5087.

Molle, G., M. Decandia, A. Cabiddu, S. Y. Landau, and A. Cannas. 2008. An update on the nutrition of dairy sheep grazing Mediterranean pastures. Small Rumin. Res. 77:93-112. https://doi.org/10 .1016/J.smallrumres.2008.03.003.

Morgavi, D. P., W. J. Kelly, P. H. Janssen, and G. T. Attwood. 2013. Ruminal microbial (meta)genomics and its application to ruminant production. Animal 7:184-201. https://doi.org/ S1751731112000419.

Moss, A. R., J.-P. Jouany, and J. Newbold. 2000. Methane production by ruminants: its contribution to global warming. Ann. Zootech. 49:231-253. https://doi.org/10.1051/animres:2000119.

Muyzer, G., E. C. De Waal, and A. G. Uitterlinden. 1993. Profiling of complex microbial populations by denaturing gradient gel electrophoresis analysis of polymerase chain reaction-amplified genes coding for 16S rRNA. Appl. Environ. Microbiol. 59:695-700.

Nathani, N. M., A. K. Patel, C. S. Mootapally, B. Reddy, S. V. Shah, P. M. Lungaria, R. K. Kothari, and C. G. Joshi. 2015. Effect of roughage on rumen microbiota composition in the efficient feed converter and sturdy Indian Jaffrabadi buffalo (Bubalus bubalis). BMC Genomics 16:1116-1131. https://doi.org/10.1186/s12864 $-015-2340-4$

Newbold, C. J., G. De La Fuente, A. Belanche, E. Ramos-Morales, and N. R. McEwan. 2015. The role of ciliate protozoa in the rumen. Front. Microbiol. 6:1313. https://doi.org/10.3389/fmicb.2015 .01313 .

Oskoueian, E., N. Abdullah, and A. Oskoueian. 2013. Effects of flavonoids on rumen fermentation activity, methane production, and microbial population. BioMed Res. Int. 2013:349129.

Pallara, G., A. Buccioni, R. Pastorelli, S. Minieri, M. Mele, S. Rapaccini, A. Messini, M. Pauselli, M. Servili, L. Giovannetti, and C. Viti. 2014. Effect of stoned olive pomace on rumen microbial communities and polyunsaturated fatty acid biohydrogenation: an in vitro study. BMC Vet. Res. 10:271. https://doi.org/10.1186/ s12917-014-0271-y.

Patra, A. K., B. R. Min, and J. Saxena. 2012. Dietary tannins on microbial ecology of the gastrointestinal tract in ruminants. Pages 237-262 in Dietary Phytochemicals and Microbes. A. K. Patra, ed. Springer, Dordrecht, the Netherlands. https://doi.org/10.1007/ 978-94-007-3926-0_8.

Patra, A. K., and J. Saxena. 2011. Exploitation of dietary tannins to improve rumen metabolism and ruminant nutrition. J. Sci. Food Agric. 91:24-37. https://doi.org/10.1002/jsfa.4152.

Paz, H. A., C. L. Anderson, M. J. Muller, P. J. Kononoff, and S. C. Fernando. 2016. Rumen bacterial community composition in holstein and jersey cows is different under same dietary condition and is not affected by sampling method. Front. Microbiol. 7:1206. https://doi.org/10.3389/fmicb.2016.01206.

Peng, S. S., M.-D. Deng, A. D. Grund, and R. A. Rosson. 2007. Purification and characterization of a membrane-bound linoleic acid isomerase from Clostridium sporogenes. Enzyme Microb. Technol. 40:831-839. https://doi.org/10.1016/j.enzmictec.2006.06.020.

Petri, R. M., C. Mapiye, M. E. R. Dugan, and T. A. McAllister. 2014. Subcutaneous adipose fatty acid profiles and related rumen bacterial populations of steers fed red clover or grass hay diets containing flax or sunflower-seed. PLoS One 9:e104167. 
Pitta, D. W., W. E. Pinchak, S. E. Dowd, J. Osterstock, V. Gontcharova, E. Youn, K. Dorton, I. Yoon, B. R. Min, J. D. Fulford, T. A. Wickersham, and D. P. Malinowski. 2010. Rumen bacterial diversity dynamics associated with changing from bermudagrass hay to grazed winter wheat diets. Microb. Ecol. 59:511-522. https://doi .org/10.1007/s00248-009-9609-6.

Priolo, A., M. Bella, M. Lanza, V. Galofaro, L. Biondi, D. Barbagallo, H. Ben Salem, and P. Pennisi. 2005. Carcass and meat quality of lambs fed fresh sulla (Hedysarum coronarium L.) with or without polyethylene glycol or concentrate. Small Rumin. Res. 59:281-288.

Puchala, R., B. R. Min, A. L. Goetsch, and T. Sahlu. 2005. The effect of a condensed tannin-containing forage on methane emission by goats. J. Anim. Sci. 83:182-186. https://doi.org/10.2527/2005 $.831182 \mathrm{x}$.

Quince, C., A. W. Walker, J. T. Simpson, N. J. Loman, and N. Segata. 2017. Shotgun metagenomics, from sampling to analysis. Nat. Biotechnol. 35:833-844. https://doi.org/10.1038/nbt.3935.

Rainio, A., M. Vahvaselkä, T. Suomalainen, and S. Laakso. 2002. Production of conjugated linoleic acid by Propionibacterium freudenreichii spp. shermanii. Lait 82:91-101. https://doi.org/10.1051/ lait:2001008.

Ramos-Morales, E., A. Arco-Pérez, A. I. Martín-García, D. R. YáñezRuiz, P. Frutos, and G. Hervás. 2014. Use of stomach tubing as an alternative to rumen cannulation to study ruminal fermentation and microbiota in sheep and goats. Anim. Feed Sci. Technol. 198:57-66. https://doi.org/10.1016/j.anifeedsci.2014.09.016.

Reck, M., J. Tomasch, Z. Deng, M. Jarek, P. Husemann, I. WagnerDöbler, and COMBACTE Consortium. 2015. Stool metatranscriptomics: A technical guideline for mRNA stabilisation and isolation. BMC Genomics 16:494. https://doi.org/10.1186/s12864-015-1694 $-\mathrm{y}$.

Rira, M., D. P. Morgavi, H. Archimede, C. Marie-Magdeleine, M. Popova, H. Bousseboua, and M. Doreau. 2015. Potential of tannin-rich plants for modulating ruminal microbes and ruminal fermentation in sheep. J. Anim. Sci. 93:334-347.

Ross, E. M., P. J. Moate, L. Marett, B. G. Cocks, and B. J. Hayes. 2013. Investigating the effect of two methane-mitigating diets on the rumen microbiome using massively parallel sequencing. J. Dairy Sci. 96:6030-6046. https://doi.org/10.3168/jds.2013-6766.

Saminathan, M., C. C. Sieo, H. M. Gan, N. Abdullah, C. M. V. L. Wong, and Y. W. Ho. 2016. Effects of condensed tannin fractions of different molecular weights on population and diversity of bovine rumen methanogenic archaea in vitro, as determined by highthroughput sequencing. Anim. Feed Sci. Technol. 216:146-160. https://doi.org/10.1016/j.anifeedsci.2016.04.005.

Schofield, P., D. M. Mbugua, and A. N. Pell. 2001. Analysis of condensed tannins: A review. Anim. Feed Sci. Technol. 91:21-40.

Seradj, A., L. Abecia, J. Crespo, D. Villalba, M. Fondevila, and J. Balcells. 2014. The effect of Bioflavex ${ }^{\circledR}$ and its pure flavonoid components on in vitro fermentation parameters and methane production in rumen fluid from steers given high concentrate diets. Anim. Feed Sci. Technol. 197:85-91. https://doi.org/10.1016/j.anifeedsci 2014.08.013

Shahidi, F., and P. Ambigaipalan. 2015. Phenolics and polyphenolics in foods, beverages and spices: Antioxidant activity and health effects - A review. J. Funct. Foods 18:820-897.

Shingfield, K. J., L. Bernard, C. Leroux, and Y. Chilliard. 2010. Role of trans fatty acids in the nutritional regulation of mammary lipogenesis in ruminants. Animal 4:1140-1166.

Silanikove, N., A. Perevolotsky, and F. D. Provenza. 2001. Use of tannin-binding chemicals to assay for tannins and their negative postingestive effects in ruminants. Anim. Feed Sci. Technol. 91:69-81.

Simister, R. L., S. Schmitt, and M. W. Taylor. 2011. Evaluating methods for the preservation and extraction of DNA and RNA for analysis of microbial communities in marine sponges. J. Exp. Mar. Biol. Ecol. 397:38-43. https://doi.org/10.1016/j.jembe.2010.11 .004 .

Sivakumaran, S., L. Meagher, L. Y. Foo, G. A. Lane, K. Fraser, and W. Rumball. 2004. Floral procyanidins of the forage legume red clover (Trifolium pratense L.). J. Agric. Food Chem. 52:1581-1585.
Snelling, T. J., B. Gneç, N. McKain, M. Watson, S. M. Waters, C. J. Creevey, and R. J. Wallace. 2014. Diversity and community composition of methanogenic archaea in the rumen of Scottish upland sheep assessed by different methods. PLoS One 9:e106491. https:/ /doi.org/10.1371/journal.pone.0106491.

Tajima, K., R. I. Aminov, T. Nagamine, H. Matsui, M. Nakamura, and Y. Benno. 2001. Diet-dependent shifts in the bacterial population of the rumen revealed with real-time PCR. Appl. Environ. Microbiol. 67:2766-2774. https://doi.org/10.1128/AEM.67.6.2766-2774 2001 .

Takahashi, S., J. Tomita, K. Nishioka, T. Hisada, and M. Nishijima. 2014. Development of a prokaryotic universal primer for simultaneous analysis of Bacteria and Archaea using next-generation sequencing. PLoS One 9:e105592. https://doi.org/10.1371/journal .pone.0105592.

Tapio, I., T. J. Snelling, F. Strozzi, and R. J. Wallace. 2017. The ruminal microbiome associated with methane emission from ruminant livestock. J. Anim. Sci. Biotechnol. 8:7. https://doi.org/10.1186/ s40104-017-0141-0.

Tavendale, M. H., L. P. Meagher, D. Pacheco, N. Walker, G. T Attwook, and S. Sivakumaran. 2005. Methane production from in vitro rumen incubations with Lotus pedunculatus, and Medicago sativa, and effects of extractable condensed tannins fractions on methanogenesis. Anim. Feed Sci. Technol. 123-124:403-419. https: //doi.org/10.1016/j.anifeedsci.2005.04.037.

Terré, M., L. Castells, F. Fàbregas, and A. Bach. 2013. Short communication: Comparison of $\mathrm{pH}$, volatile fatty acids, and microbiome of rumen samples from preweaned calves obtained via cannula or stomach tube. J. Dairy Sci. 96:5290-5294. https://doi.org/10 .3168/jds.2012-5921.

Toral, P. G., B. A. Belenguer, K. J. Shingfield, G. Hervas, V. Toivonen, and P. Frutos. 2012. Fatty acid composition and bacterial community changes in the rumen fluid of lactating sheep fed sunflower oil plus incremental levels of marine algae. J. Dairy Sci. 95:794-806.

Toral, P. G., G. Hervás, E. Bichi, A. Belenguer, and P. Frutos. 2011. Tannins as fed additives to modulate ruminal biohydrogenation: Effects on animal performance, milk fatty acid composition and ruminal fermentation in dairy ewes fed a diet containing sunflower oil. Anim. Feed Sci. Technol. 164:199-206. https://doi.org/10 .1016/j.anifeedsci.2011.01.011.

Unni, K. N., P. Priji, S. Sajith, P. A. Faisal, and S. Benjamin. 2016. Pseudomonas aeruginosa strain BUP2, a novel bacterium inhabiting the rumen of Malabari goat, produces an efficient lipase. Biologia 71:378-387.

van de Vossenberg, J. L., and K. N. Joblin. 2003. Biohydrogenation of $\mathrm{C} 18$ unsaturated fatty acids to stearic acid by a strain of $\mathrm{Bu}$ tyrivibrio hungatei from the bovine rumen. Lett. Appl. Microbiol. $37: 424-428$

Vargas, J. E., S. Andrés, T. J. Snelling, L. López-Ferreras, D. R. Yáñez-Ruíz, C. García-Estrada, and S. López. 2017. Effect of sunflower and marine oils on ruminal microbiota, in vitro fermentation and digesta fatty acid profile. Front. Microbiol. 8:1124. https: //doi.org/10.3389/fmicb.2017.01124.

Vasta, V., and R. J. B. Bessa. 2012. Manipulating ruminal biohydrogenation by the use of plants bioactive compounds. Pages 263-284 in Dietary Phytochemicals and Microbes. A. K. Patra, ed. Springer, Dordrecht, the Netherlands. https://doi.org/10.1007/978-94-007 -3926-0_9.

Vasta, V., and G. Luciano. 2011. The effects of dietary consumption of plants secondary compounds on small ruminants' products quality. Small Rumin. Res. 101:150-159. https://doi.org/10.1016/ j.smallrumres.2011.09.035.

Vasta, V., H. P. S. Makkar, M. Mele, and A. Priolo. 2009b. Ruminal biohydrogenation as affected by tannins in vitro. Br. J. Nutr. 102:82-92. https://doi.org/10.1017/S0007114508137898.

Vasta, V., M. Mele, A. Serra, M. Scerra, G. Luciano, M. Lanza, and A. Priolo. 2009a. Metabolic fate of fatty acids involved in ruminal biohydrogenation in sheep fed concentrate or herbage with or without tannins. J. Anim. Sci. 87:2674-2684. https://doi.org/10 $.2527 /$ jas.2008-1761. 
Vasta, V., A. Nudda, A. Cannas, M. Lanza, and A. Priolo. 2008. Alternative feed resources and their effects on the quality of meat and milk from small ruminants. Anim. Feed Sci. Technol. 147:223-246. https://doi.org/10.1016/j.anifeedsci.2007.09.020.

Vasta, V., D. R. Yáñez-Ruiz, M. Mele, A. Serra, G. Luciano, M. Lanza, L. Biondi, and A. Priolo. 2010. Bacterial and protozoal communities and fatty acid profile in the rumen of sheep fed a diet containing added tannins. Appl. Environ. Microbiol. 76:2549-2555. https: //doi.org/10.1128/AEM.02583-09.

Verhulst, A., G. Parmentier, G. Janssen, S. Asselberghs, and H. Eyssen. 1986. Biotransformation of unsaturated long-chain fatty acids by Eubacterium lentum. Appl. Environ. Microbiol. 51:532-538.

Vincent, A. T., N. Derome, B. Boyle, A. I. Culley, and S. J. Charette. 2017. Next-generation sequencing (NGS) in the microbiological world: how to make the most of your money. J. Microbiol. Methods 138:60-71. https://doi.org/10.1016/j.mimet.2016.02.016.

Waghorn, G. C. 2008. Beneficial and detrimental effects of dietary condensed tannins for sustainable sheep and goat production Progress and challenges. Anim. Feed Sci. Technol. 147:116-139. https://doi.org/10.1016/j.anifeedsci.2007.09.013.

Wallace, R. J. 2008. Gut microbiology - Broad genetic diversity, yet specific metabolic niches. Animal 2:661-668. https://doi.org/10 $.1017 /$ S1751731108001687.

Wallace, R. J., L. C. Chaudhary, N. McKain, N. R. McEwan, A. J. Richardson, P. E. Vercoe, N. D. Walker, and D. Paillard. 2006. Clostridium proteoclasticum: A ruminal bacterium that forms stearic acid from linoleic acid. FEMS Microbiol. Lett. 265:195-201. https://doi.org/10.1111/j.1574-6968.2006.00487.x.

Wallace, R. J., J. A. Rooke, N. McKain, C. A. Duthie, J. J. Hyslop, D. W. Ross, A. Waterhouse, M. Watson, and R. Roehe. 2015. The rumen microbial metagenome associated with high methane production in cattle. BMC Genomics 16:839. https://doi.org/10 .1186/s12864-015-2032-0.

Wallace, R. J., T. J. Snelling, C. A. McCartney, I. Tapio, and F. Strozzi. 2017. Application of meta-omics techniques to understand greenhouse gas emissions originating from ruminal metabolism. Genet. Sel. Evol. 49:9.

Wang, L., Q. Xu, F. Kong, Y. Yang, D. Wu, S. Mishra, and Y. Li. 2016. Exploring the got rumen microbiome from seven days to two years. PLoS One 11:e0154354. https://doi.org/10.1371/journal .pone.0154354.

Wang, P., M. Qi, P. Barboza, M. B. Leigh, E. Ungerfeld, L. B. Selinger, T. A. McAllister, and R. J. Forster. 2011. Isolation of high-quality total RNA from rumen anaerobic bacteria and fungi, and subsequent detection of glycoside hydrolases. Can. J. Microbiol. 57:590598. https://doi.org/10.1139/w11-048.

Wang, Y., and P. Y. Qian. 2009. Conservative fragments in bacterial $16 \mathrm{~S}$ rRNA genes and primer design for $16 \mathrm{~S}$ ribosomal DNA amplicons in metagenomic studies. PLoS One 4:e7401. https://doi.org/ 10.1371/journal.pone.0007401.

Weimer, P. J. 2015. Redundancy, resilience, and host specificity of the ruminal microbiota: Implications for engineering improved ruminal fermentations. Front. Microbiol. 6:296. https://doi.org/10.3389/ fmicb.2015.00296.

Witzig, M., M. Zeder, and M. Rodehutscord. 2018. Effect of the ionophore monensin and tannin extracts supplemented to grass silage on populations of ruminal cellulolytics and methanogens in vitro. Anaerobe 50:44-54.

Yang, K., C. Wei, G. Y. Zhao, Z. W. Xu, and S. X. Lin. 2017. Effects of dietary supplementing tannic acid in the ration of beef cattle on rumen fermentation, methane emission, microbial flora and nutrient digestibility. J. Anim. Physiol. Anim. Nutr. (Berl.) 101:302-310. https://doi.org/10.1111/jpn.12531.

Yusuf, A. L., K. D. Adeyemi, A. A. Samsudin, Y. M. Jafari, A. R. Alimon, and A. Q. Sazili. 2017. Effects of dietary supplementation of leaves and whole plant of Andrographis paniculata on rumen fermentation, fatty acid composition and microbiota in goats. BMC Vet. Res. 13:349. https://doi.org/10.1186/s12917-017-1223-0.

Ziolecki, A. 1979. Isolation and characterization of large treponemes from the bovine rumen. Appl. Environ. Microbiol. 37:131-135. 